\title{
Formaldehyde Distribution over North America: Implications for Satellite Retrievals of Formaldehyde Columns and Isoprene Emission
}

\section{Citation}

Millet, Dylan B., Daniel J. Jacob, Solene Turquety, Rynda C. Hudman, Shiliang Wu, Alan Fried, James Walega, et al. 2006. Formaldehyde distribution over North America: Implications for satellite retrievals of formaldehyde columns and isoprene emission. Journal of Geophysical Research 111: D24S02.

\section{Published Version}

doi:10.1029/2005JD006853

\section{Permanent link}

http://nrs.harvard.edu/urn-3:HUL.InstRepos:3743792

\section{Terms of Use}

This article was downloaded from Harvard University's DASH repository, and is made available under the terms and conditions applicable to Other Posted Material, as set forth at http:// nrs.harvard.edu/urn-3:HUL.InstRepos:dash.current.terms-of-use\#LAA

\section{Share Your Story}

The Harvard community has made this article openly available.

Please share how this access benefits you. Submit a story.

Accessibility 


\section{Formaldehyde distribution over North America: Implications for satellite retrievals of formaldehyde columns and isoprene emission}

Dylan B. Millet, ${ }^{1}$ Daniel J. Jacob, ${ }^{1}$ Solène Turquety, ${ }^{1,2}$ Rynda C. Hudman, ${ }^{1}$ Shiliang Wu, ${ }^{1}$ Alan Fried, ${ }^{3}$ James Walega, ${ }^{3}$ Brian G. Heikes, ${ }^{4}$ Donald R. Blake, ${ }^{5}$ Hanwant B. Singh, ${ }^{6}$ Bruce E. Anderson, ${ }^{7}$ and Antony D. Clarke ${ }^{8}$

Received 5 November 2005; revised 20 January 2006; accepted 27 March 2006; published 8 September 2006.

[1] Formaldehyde $(\mathrm{HCHO})$ columns measured from space provide constraints on emissions of volatile organic compounds (VOCs). Quantitative interpretation requires characterization of errors in $\mathrm{HCHO}$ column retrievals and relating these columns to VOC emissions. Retrieval error is mainly in the air mass factor (AMF) which relates fitted backscattered radiances to vertical columns and requires external information on $\mathrm{HCHO}$, aerosols, and clouds. Here we use aircraft data collected over North America and the Atlantic to determine the local relationships between HCHO columns and VOC emissions, calculate AMFs for $\mathrm{HCHO}$ retrievals, assess the errors in deriving AMFs with a chemical transport model (GEOS-Chem), and draw conclusions regarding space-based mapping of VOC emissions. We show that isoprene drives observed HCHO column variability over North America; HCHO column data from space can thus be used effectively as a proxy for isoprene emission. From observed $\mathrm{HCHO}$ and isoprene profiles we find an HCHO molar yield from isoprene oxidation of $1.6 \pm 0.5$, consistent with current chemical mechanisms. Clouds are the primary error source in the AMF calculation; errors in the $\mathrm{HCHO}$ vertical profile and aerosols have comparatively little effect. The mean bias and $1 \sigma$ uncertainty in the GEOS-Chem AMF calculation increase from $<1 \%$ and $15 \%$ for clear skies to $17 \%$ and $24 \%$ for half-cloudy scenes. With fitting errors, this gives an overall $1 \sigma$ error in $\mathrm{HCHO}$ satellite measurements of $25-31 \%$. Retrieval errors, combined with uncertainties in the $\mathrm{HCHO}$ yield from isoprene oxidation, result in a $40 \%(1 \sigma)$ error in inferring isoprene emissions from $\mathrm{HCHO}$ satellite measurements.

Citation: Millet, D. B., et al. (2006), Formaldehyde distribution over North America: Implications for satellite retrievals of formaldehyde columns and isoprene emission, J. Geophys. Res., 111, D24S02, doi:10.1029/2005JD006853.

\section{Introduction}

[2] Atmospheric volatile organic compounds (VOCs) are precursors of tropospheric ozone and secondary organic aerosol, and play an important role in $\mathrm{HO}_{\mathrm{x}}$ and $\mathrm{NO}_{\mathrm{y}}$ radical cycling. Bottom-up VOC emission estimates, relying on extrapolation of point measurements to regional and larger

\footnotetext{
${ }^{1}$ Department of Earth and Planetary Sciences and Division of Engineering and Applied Sciences, Harvard University, Cambridge, Massachusetts, USA.

${ }^{2}$ Now at Service d'Aéronomie, Institut Pierre-Simon Laplace, Paris, France.

${ }^{3}$ Earth Observing Laboratory, National Center for Atmospheric Research, Boulder, Colorado, USA.

${ }^{4}$ Graduate School of Oceanography, University of Rhode Island, Narragansett, Rhode Island, USA.

${ }^{5}$ Department of Chemistry, University of California, Irvine, California, USA.

${ }^{6}$ NASA Ames Research Center, Moffett Field, California, USA.

${ }^{7}$ Atmospheric Sciences Division, NASA Langley Research Center, Hampton, Virginia, USA.

${ }^{8}$ School of Ocean and Earth Science and Technology, University of Hawaii at Manoa, Honolulu, Hawaii, USA.
}

Copyright 2006 by the American Geophysical Union. 0148-0227/06/2005JD006853\$09.00 scales, are inherently uncertain. Formaldehyde (HCHO), which is produced in high yield during the atmospheric oxidation of VOCs, absorbs in the near-UV and can be measured as a column integral from satellite-borne solar backscatter instruments [Burrows et al., 1999; Chance et al., 2000]. Such measurements offer the means to derive global, top-down constraints on surface emissions of VOCs. In order to do so reliably we need to quantify the errors associated with the column measurements and their relationship to precursor emissions. Here we use 69 aircraft vertical profiles over North America collected during the Intercontinental Chemical Transport Experiment (INTEX-A) aircraft campaign in summer 2004 (H. B. Singh et al., Overview of the summer 2004 Intercontinental Chemical Transport Experiment-North America (INTEX-A), submitted to Journal of Geophysical Research, 2006) to quantify the dominant errors in satellite retrievals of $\mathrm{HCHO}$ columns, and determine how the $\mathrm{HCHO}$ column and its variability can be interpreted in terms of the underlying reactive $\mathrm{VOC}$ emissions.

[3] While oxidation of methane is the main HCHO source in the remote atmosphere [Lowe and Schmidt, 1983; Singh et al., 2000; Heikes et al., 2001; Frost et al., 2002; Wagner et al., 2002], more reactive VOCs frequently dominate in 
the continental boundary layer [Lee et al., 1998; Fried et al., 2003]. The main HCHO sinks are reaction with the hydroxyl radical and photolysis [Levy, 1972], which combine to give an atmospheric lifetime of a few hours in daytime [Atkinson, 2000].

[4] Isoprene, a highly reactive compound which is the principal VOC emitted from vegetation [Zimmerman et al., 1978; Fehsenfeld et al., 1992; Fuentes et al., 2000; Guenther et al., 2000], is in particular a major source of $\mathrm{HCHO}$ during the growing season [Zimmerman et al., 1978; Hanst et al., 1980; Shepson et al., 1991; Lee et al., 1998]. Globally, emissions of isoprene are estimated to be around $500 \mathrm{Tg} \mathrm{yr}^{-1}$ [Guenther et al., 1995; Wang and Shallcross, 2000; Potter et al., 2001; Levis et al., 2003; Sanderson et al., 2003; Naik et al., 2004; Guenther et al., 2006], substantially greater than the total VOC emissions from all anthropogenic sources [Singh and Zimmerman, 1992]. Even over densely populated and industrialized eastern North America, on regional scales isoprene far exceeds anthropogenic VOC emissions during the growing season [Jacob et al., 1993] and is a major source of surface ozone [Fiore et al., 2005] and also possibly organic aerosol [Jang et al., 2002; Czoschke et al., 2003; Limbeck et al., 2003; Claeys et al., 2004a, 2004b; Zhang et al., 2004; Lim et al., 2005].

[5] Despite considerable efforts in constructing bottomup emission inventories for isoprene and other biogenic VOCs, important uncertainties remain because of the need to extrapolate over vegetation types, the complex effects of environmental stressors, and evolving land cover [Guenther et al., 2000]. Palmer et al. [2001, 2003] developed a topdown approach for inferring isoprene emission fluxes using space-based column measurements of $\mathrm{HCHO}$, and applied it to derive emissions from North America using data from the Global Ozone Monitoring Experiment (GOME) satellite instrument. This work has since been extended to examine seasonal and interannual variability in North American isoprene emissions [Abbot et al., 2003; Palmer et al., 2006]. Recently, Shim et al. [2005] carried out a Bayesian inversion of GOME HCHO column measurements for different continental source regions, and derived global isoprene emissions $50 \%$ larger than the a priori estimate.

[6] Work to date in this area has used data from GOME, which has $40 \mathrm{~km} \times 320 \mathrm{~km}$ resolution and global coverage every three days. The Ozone Monitoring Instrument (OMI), which was launched in 2004 aboard the NASA Aura satellite, provides daily global coverage and a footprint of $13 \times 24 \mathrm{~km}$. HCHO columns measured from OMI should enable us to quantify surface fluxes of VOCs at a far greater level of temporal and spatial detail than is possible with GOME. The validity of such analyses depends on the uncertainties associated with the retrieval of $\mathrm{HCHO}$ vertical columns from the satellite spectra and with their interpretation in terms of VOC emission. The dominant source of error in the retrieval is the air mass factor (AMF) [Palmer et al., 2006], which defines the relationship between the HCHO abundance along the viewing path of the satellite instrument ("slant column") and the vertical column amount [Noxon et al., 1979; Perliski and Solomon, 1993; Marquard et al., 2000; Palmer et al., 2001; Hild et al., 2002; Richter and Burrows, 2002; Boersma et al., 2004]. The AMF calculation requires external information on atmospheric scattering by air molecules, clouds and aerosols, on the shape of the $\mathrm{HCHO}$ vertical distribution, and on the UV albedo of the surface. Clouds, which increase instrument sensitivity to the absorber above the cloud while decreasing it below, represent a significant source of uncertainty in the computation of the AMF [Koelemeijer and Stammes, 1999; Velders et al., 2001; Richter and Burrows, 2002; Martin et al., 2003a; Boersma et al., 2004]. The interpretation of observed $\mathrm{HCHO}$ columns in terms of precursor VOC emissions also requires prior information on the relationship between the VOC surface flux and the resulting $\mathrm{HCHO}$ column amount.

[7] INTEX-A included numerous aircraft profiles over North America. The resulting data set, which includes measurements of HCHO together with VOCs, aerosol extinction, and cloud extinction, provides us with an excellent opportunity to go beyond previous work and quantify the errors involved in relating satellite $\mathrm{HCHO}$ measurements to VOC emissions. In the present study, we use the INTEX-A aircraft data and output from the GEOS-Chem chemical transport model (CTM) to (1) determine the important precursors contributing to $\mathrm{HCHO}$ columns and variability over North America, and quantify the relationships between precursor emissions and HCHO columns; (2) carry out a statistically meaningful and geographically extensive quantification of the errors in the AMF calculation; and (3) draw conclusions regarding the mapping of VOC emissions from space.

\section{Background}

\subsection{Satellite Retrievals of HCHO Columns}

[8] The retrieval of atmospheric HCHO column abundance using space-borne solar backscatter instruments can be performed by fitting the backscattered spectrum in the $\mathrm{HCHO}$ absorption window (337-356 nm) to modeled atmospheric spectra [e.g., Chance et al., 2000], or by differential optical absorption spectroscopy [e.g., Leue et al., 2001]. The resulting $\mathrm{HCHO}$ abundance integrated along the viewing path is called the slant column, and the ratio of the slant column to the actual vertical column is termed the AMF. In the case of a nonscattering atmosphere, the geometric air mass factor $\mathrm{AMF}_{\mathrm{G}}$ would be determined solely by the satellite viewing angle $\left(\theta_{V}\right)$ and the solar zenith angle $\left(\theta_{S}\right)$ :

$$
\mathrm{AMF}_{\mathrm{G}}=\sec \theta_{S}+\sec \theta_{V}
$$

This simple expression must be corrected for scattering by air molecules, clouds, and aerosols, which results in sensitivity to the vertical distribution of the absorbing gas and to the surface albedo. The correction factor can be expressed in the optically thin case as an integral of sensitivity over the depth of the atmosphere [Palmer et al., 2001]:

$$
\mathrm{AMF}=\frac{\mathrm{AMF}_{\mathrm{G}}}{P_{S}} \int_{P_{S}}^{0} w(P) S(P) \mathrm{d} P,
$$

where $P$ is pressure and $P_{\mathrm{S}}$ is the pressure at Earth's surface. The scattering weights $w(P)$ represent the sensitivity of the 
backscattered radiation measured from space to the abundance of the absorber (here $\mathrm{HCHO}$ ) at pressure $P$, and are determined using a radiative transfer model. The shape factor $S(P)$ is the normalized vertical profile of mixing ratio of the absorber, and is determined from typical atmospheric observations or an atmospheric CTM. Aerosol vertical profiles for the radiative transfer calculation are similarly specified from climatologies [Velders et al., 2001; Richter and Burrows, 2002; Beirle et al., 2004; Richter et al., 2004; Savage et al., 2004], or from the same CTM used to specify $S(P)$ [Martin et al., 2003a; Jaeglé et al., 2004]. Like clouds, aerosols can act to either increase or decrease the instrument sensitivity to $\mathrm{HCHO}$, depending on the single scattering albedo of the aerosol and its vertical distribution relative to the absorber.

[9] Satellite viewing scenes are typically partly cloudy, particularly for an instrument with a large footprint such as GOME. The ability to resolve partly cloudy scenes in the retrieval is thus critical to the data coverage. In the case of GOME, broadband polarization monitoring devices provide information on cloud fraction, and spectral fitting in and around the oxygen A-band provides information on cloud top altitude and cloud optical depth [Kurosu et al., 1999; Koelemeijer et al., 2001]. Previous GOME retrievals for $\mathrm{HCHO}$ or $\mathrm{NO}_{2}$ have either assumed cloud effects to be negligible for pixels having cloud fractions below a given threshold [Palmer et al., 2001; Lauer et al., 2002; Richter and Burrows, 2002; Ladstatter-Weissenmayer et al., 2003; Palmer et al., 2003; Stohl et al., 2003; Beirle et al., 2004; Richter et al., 2004; Savage et al., 2004; Irie et al., 2005; Konovalov et al., 2005], applied a constant correction factor to cloudy scenes [Leue et al., 2001; Velders et al., 2001; Beirle et al., 2003], or calculated the radiative transfer through clouds explicitly using local cloud information [Martin et al., 2002a; Abbot et al., 2003; Martin et al., 2003a; Jaeglé et al., 2004; Palmer et al., 2006].

[10] In the latter approach, developed by Martin et al. [2002a], the AMF for a partly cloudy scene is derived as the weighted sum of the values for the clear and cloudy subscenes:

$$
\mathrm{AMF}=\frac{\mathrm{AMF}_{\text {clear }} R_{\text {clear }}(1-f)+\mathrm{AMF}_{\text {cloud }} R_{\text {cloud }} f}{R_{\text {clear }}(1-f)+R_{\text {cloud }} f}
$$

where $f$ is the cloud fraction, and $R_{\text {clear }}$ and $R_{\text {cloud }}$ are the reflectivities of the clear and cloudy portions of the retrieval scene. The two subscenes are assumed to have the same HCHO shape factor $S(P)$. Martin et al. [2002a] and the subsequent studies calculated the AMF for the cloudy subscene by using the GOME information on cloud top and optical depth, and distributing the cloud extinction vertically assuming an optical thickness increment of 8 for each $100 \mathrm{hPa}$ below cloud top.

[11] The primary uncertainties in space-borne measurements of $\mathrm{HCHO}$ columns arise from the slant column fitting [Chance et al., 2000], which defines the instrumental detection limit, and errors in the AMF, which define a relative error for columns well above the detection limit [Palmer et al., 2001; Martin et al., 2002a; Boersma et al., 2004; Palmer et al., 2006]. The slant column fitting uncertainty is $4 \times 10^{15}$ molecules $\mathrm{cm}^{-2}$ for GOME. The main sources of error in the AMF are the surface albedo, specification of the
HCHO vertical profile, and aerosol and cloud effects, and quantification of this error is a focus of our paper.

\subsection{Relating HCHO Columns to Precursor Emissions}

[12] Column HCHO measurements from space can be used to derive precursor emission fluxes [Palmer et al., 2003], provided the associated HCHO production yields are known. At steady state and in the absence of horizontal transport, the HCHO column $\left(\Omega_{\mathrm{HCHO}}\right.$, molecules $\left.\mathrm{cm}^{-2}\right)$ would be related to the emissions of precursors $i$ by

$$
\Omega_{\mathrm{HCHO}}=\frac{1}{k_{\mathrm{HCHO}}} \sum_{i} k_{i} Y_{i} \Omega_{i}=\frac{1}{k_{\mathrm{HCHO}}} \sum_{i} Y_{i} E_{i},
$$

where $k_{\mathrm{HCHO}}$ and $k_{i}$ are the column-average effective rate constants $\left(\mathrm{s}^{-1}\right)$ for chemical loss of $\mathrm{HCHO}$ and precursor $i$, $Y_{i}$ is the molar HCHO yield from the oxidation of species $i$, and $E_{i}$ is the emission flux. Horizontal transport smears this relationship, resulting in a spatial offset between the $\mathrm{HCHO}$ column and the location of precursor emission, and diluting the HCHO signal associated with the emission [Palmer et al., 2003]. For isoprene, which has a lifetime in summer of $\sim 0.5 \mathrm{~h}$ and yields $\mathrm{HCHO}$ in its first generation of products, the smearing length scale is only $10-100 \mathrm{~km}$, smaller than the GOME pixel size [Palmer et al., 2003]. For longer-lived VOCs or VOCs with delayed HCHO production, the smearing length scale may be sufficiently large to dilute the HCHO signal to below the fitting uncertainty [Palmer et al., 2006]. This smearing effect will limit gains in spatial resolution otherwise achievable with new satellite instruments unless inverse methods are developed that account for fine-scale VOC transport and chemistry.

[13] Inferring VOC emission fluxes from observed $\mathrm{HCHO}$ columns requires assumptions about the $\mathrm{HCHO}$ yield $Y_{i}$. Palmer et al. [2006] computed the time-dependent $\mathrm{HCHO}$ yield from isoprene oxidation using two independent mechanisms, GEOS-Chem (http://www.as.harvard. edu/chemistry/trop/geos/index.html) [Horowitz et al., 1998; Evans and Jacob, 2005] and the Master Chemical Mechanism (MCM) v. 3.1 [Bloss et al., 2005]. They found the yield calculated by MCM to be $20-30 \%$ higher than that derived by GEOS-Chem. The resulting HCHO molar yields after one day under low- $\mathrm{NO}_{\mathrm{x}}(0.1 \mathrm{ppb})$ conditions are 0.9 (GEOS-Chem) and 1.6 (MCM). The high-NO $\mathrm{NO}_{\mathrm{x}}(1 \mathrm{ppb})$ molar yields are 1.9 (GEOS-Chem) and 2.4 (MCM).

\section{Approach}

[14] The previous section has highlighted a number of uncertainties in the derivation of VOC emissions from spacebased HCHO column measurements. In this section we describe our use of the INTEX-A aircraft measurements to better quantify these uncertainties and thus improve the constraints on the top-down VOC emission estimates. We use the GEOS-Chem CTM as the source of external information here but our findings can be applied to any CTMassisted retrieval.

\subsection{Measurements}

[15] The primary objective of INTEX-A (1 July to 15 August 2004) was to observe the chemical outflow from North America and infer constraints on chemical sources 


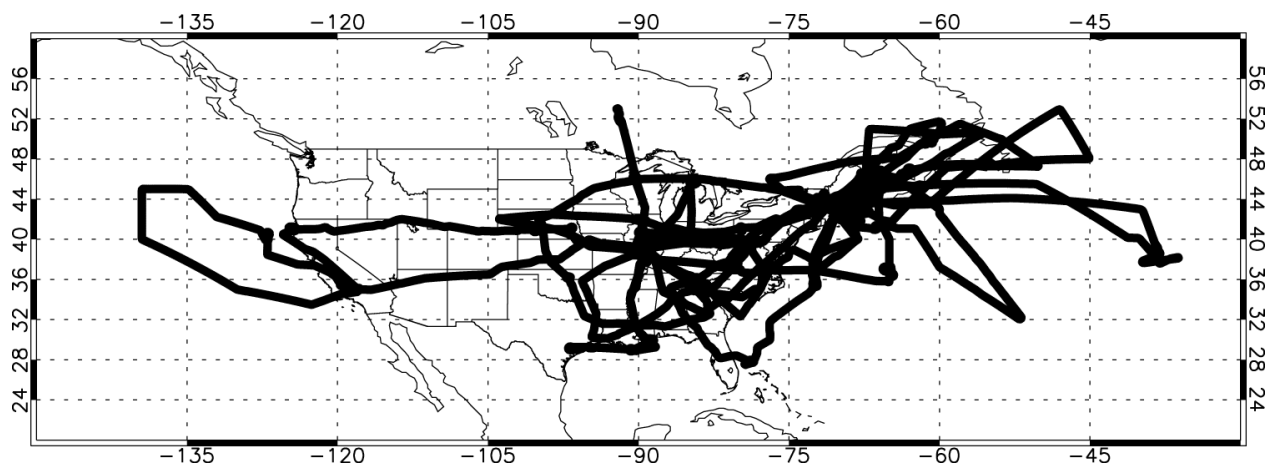

Figure 1. DC-8 flight tracks during INTEX-A.

and export. Here we use measurements of $\mathrm{HCHO}$ and related tracers made aboard the NASA DC-8 aircraft (ceiling $12 \mathrm{~km}$ ) over North America and the adjacent oceans during INTEX-A. The DC-8 aircraft flew 18 science flights between 1 July and 15 August with extensive vertical profiling from the boundary layer to the upper troposphere. All flights took place during daytime, typically from 1000 to 1800 local time. The flight tracks are shown in Figure 1.

[16] HCHO measurements were carried out by two groups, from the National Center for Atmospheric Research (NCAR) and the University of Rhode Island (URI) (hereafter referred to as the NCAR and URI measurements, respectively). HCHO was measured by the NCAR group using tunable diode laser absorption spectroscopy [Wert et al., 2003; Roller et al., 2006; A. Fried et al., The role of convection in redistributing formaldehyde to the upper troposphere over North America and the North Atlantic during the summer 2004 INTEX campaign, manuscript in preparation, 2006, hereinafter referred to as Fried et al., manuscript in preparation, 2006]. The total calibration uncertainty is estimated to be $\pm 12 \%(2 \sigma)$, and the limit of detection (LOD) is $77 \mathrm{ppt}$ for the first part of the mission and $66 \mathrm{ppt}$ for the last 7 flights (31 July 2004 to 14 August 2004), for 1 -min averaged data (both $2 \sigma$ ). The measurement precision is the same as the LOD over the HCHO mixing ratios measured during INTEX-A. The URI HCHO measurement was performed using aqueous collection and enzyme-fluorescence detection [Heikes et al., 2001]. The LOD is $50 \mathrm{ppt}$ for the first part of the mission, and $25 \mathrm{ppt}$ for the last 5 flights (6-14 August 2004). The total uncertainty in the measurement is estimated at $\pm(33 \mathrm{ppt}+$ $0.15^{*}[\mathrm{HCHO}$ mixing ratio]). Measurements from the two groups were highly correlated over the ensemble of the INTEX-A mission $\left(\mathrm{R}^{2}=0.89\right)$. However, a reduced major axis regression of the two data sets yields a slope of 0.69 , with the URI data being lower than the NCAR data. A detailed measurement intercomparison is presented elsewhere (Fried et al., manuscript in preparation, 2006).

[17] Oxygenated VOCs were measured with a sampling frequency of 2.5-5 min using cryogenic preconcentration, gas chromatographic (GC) separation, and detection by photoionization detector and reduction gas detector [Singh et al., 2004]. Detection limits range from 5 to $20 \mathrm{ppt}$, and the sensitivity and precision of measurement are approximately $20 \%$ and $10 \%$. Hydrocarbons were measured by whole air sampling followed by cryogenic preconcentration, GC separation, and detection by flame ionization detector and mass selective detector [Colman et al., 2001; Blake et al., 2003]. Calibration was based on whole air standards (for $<\mathrm{C}_{8}$ gases) and per-carbon response factors (for $\mathrm{C}_{8}-\mathrm{C}_{10}$ gases). The limit of detection is approximately $3 \mathrm{ppt}$ for the species reported here. The measurement precision and overall accuracy are $1-3 \%$ and $2-10 \%$, respectively, depending on the compound.

[18] Aerosol scattering coefficients were measured at 450, 550, and $700 \mathrm{~nm}$ using two TSI 3563 three-wavelength integrating nephelometers. The value at $346 \mathrm{~nm}$ was estimated from the Angstrom exponent derived from the $450 \mathrm{~nm}$ and $550 \mathrm{~nm}$ measurements. Aerosol absorption coefficients at 470, 530 and $660 \mathrm{~nm}$ were measured using a pair of Radiance Research Particle Soot Absorption Photometers [Bond et al., 1999; Virkkula et al., 2005]; the absorption coefficient at $346 \mathrm{~nm}$ was assumed equal to that at $470 \mathrm{~nm}$.

\subsection{Model Description}

[19] Atmospheric distributions of $\mathrm{HCHO}$ and related tracers were simulated for the INTEX-A period using the GEOS-Chem global 3D CTM [Bey et al., 2001; Park et al., 2004]. The GEOS-Chem CTM (version 7.02, http://www. as.harvard.edu/chemistry/trop/geos/index.html) uses GEOS-4 assimilated meteorological data from the NASA Goddard Earth Observing System including winds, convective mass fluxes, mixing depths, temperature, precipitation, and surface properties. The data have 6-hour temporal resolution (3-hour for surface variables and mixing depths), $1^{\circ} \times 1.25^{\circ}$ horizontal resolution, and 55 vertical layers. We degrade the horizontal resolution to $2^{\circ} \times 2.5^{\circ}$ for input to GEOS-Chem.

[20] The model includes detailed ozone- $\mathrm{NO}_{\mathrm{x}}-\mathrm{VOC}$ chemistry coupled to aerosols. Global emissions are as described by Bey et al. [2001], with recent updates [Martin et al., 2002b; Park et al., 2004; Xiao et al., 2004]. Isoprene emissions are calculated using the GEIA inventory [Guenther et al., 1995]. Anthropogenic emissions from North America are based on the EPA NEI 1999 v.1 inventory (http://www.epa.gov/ttn/chief/net/1999inventory. html). The aerosol simulation is as described by Park et al. [2003, 2004], and includes sulfate-nitrate-ammonium, organic and black carbon, size-resolved soil dust, and sizeresolved sea salt. Aerosol optical thicknesses are calculated from the mass concentrations and optical properties for each aerosol type, as a function of local relative humidity, following Martin et al. [2003b]. Previous studies have compared GEOS-Chem results with observations over North America and the North Atlantic for HCHO [Singh 


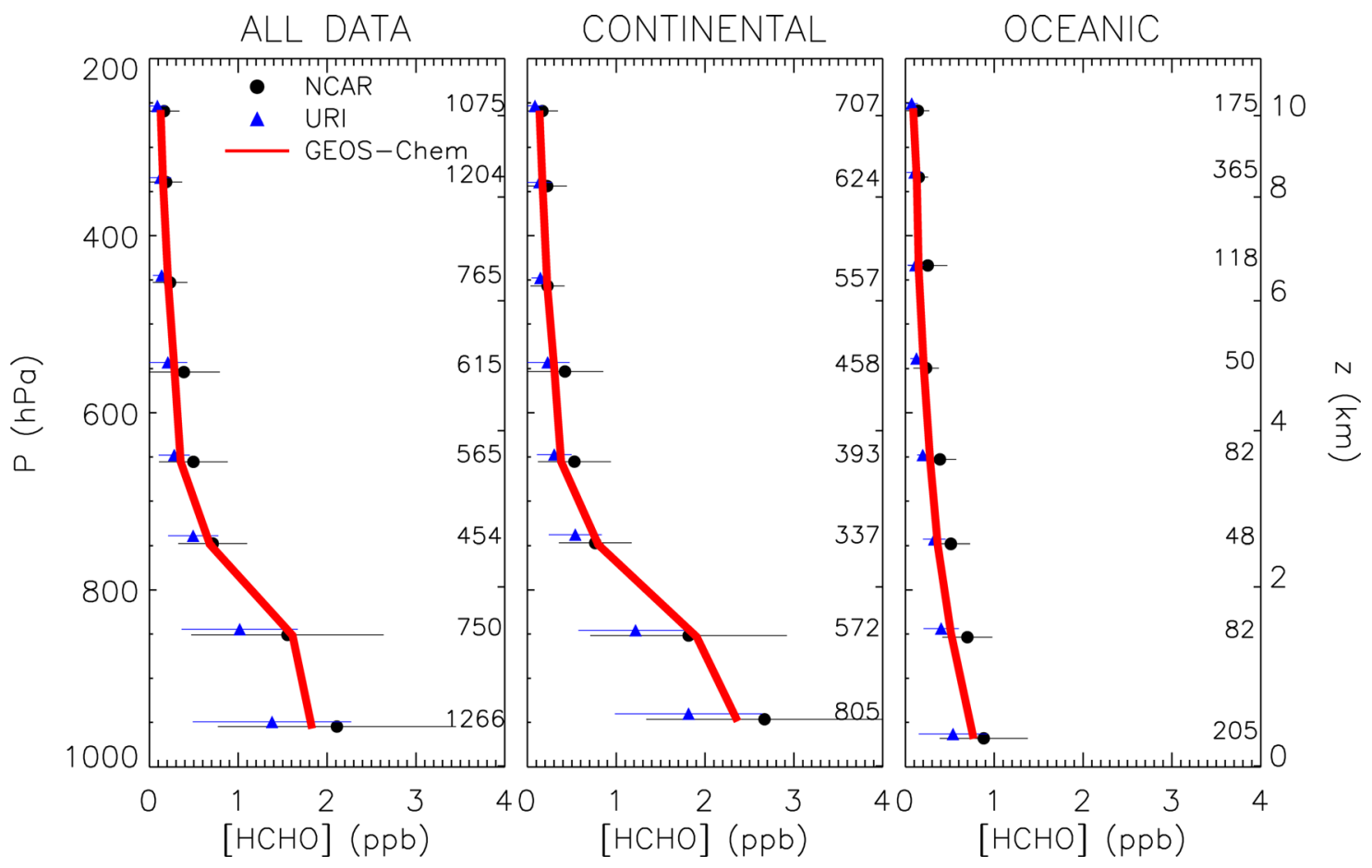

Figure 2. Mean simulated (lines) and observed (symbols) HCHO vertical distributions during INTEX-A, calculated for $100 \mathrm{hPa}$ vertical bins. Error bars represent observed standard deviations (the numbers of points are indicated on the right). The vertical coordinates for the URI observations are offset slightly for visibility. Here and elsewhere, the model is sampled along the flight tracks and for the time of the measurements.

et al., 2000; Palmer et al., 2001; Fiore et al., 2002; Martin et al., 2004] and aerosols [Park et al., 2003, 2004; A. van Donkelaar et al., Model evidence for a significant source of secondary organic aerosol from isoprene, submitted to Atmospheric Environment, 2006]. The current simulation was conducted at $2^{\circ} \times 2.5^{\circ}$ horizontal resolution and with 30 vertical layers. Results are presented here for July and August 2004, and follow a 1 year spin-up.

[21] Applications of GEOS-Chem to simulation of other aspects of INTEX-A data include analyses of North American $\mathrm{NO}_{\mathrm{x}}$ emissions and reactive nitrogen export (R. C. Hudman et al., Surface and lightning sources of nitrogen oxides over the United States: Magnitudes, chemical evolution, and outflow, submitted to Journal of Geophysical Research, 2006, hereinafter referred to as Hudman et al., submitted manuscript, 2006), boreal fire emissions (S. Turquety et al., Inventory of boreal fire emissions for North America in 2004: The importance of peat burning and pyro-convective injection, submitted to Journal of Geophysical Research, 2006), Asian inflow (Q. Liang et al., Summertime influence of Asian pollution in the free troposphere over North America, submitted to Journal of Geophysical Research, 2006).

\section{Atmospheric Distribution of HCHO Over North America}

\subsection{Vertical Distributions}

[22] Mean observed and simulated vertical distributions of $\mathrm{HCHO}$ are displayed in Figure 2, for the ensemble of the data, as well as continental and oceanic subsets. Here and elsewhere, the model is sampled along the flight tracks and for the times of the measurements. Mixing ratios are high in the continental boundary layer because of surface emissions of $\mathrm{HCHO}$ precursors, and decrease rapidly with altitude because of the short HCHO lifetime. Mixing ratios over the ocean are lower and decrease more gradually with altitude, reflecting primarily the temperature dependence of methane oxidation. Observed continental mixing ratios decrease from a mean of $1800 \mathrm{ppt}$ (URI) to $2700 \mathrm{ppt}$ (NCAR) near the surface to $230 \mathrm{ppt}$ (URI) to $420 \mathrm{ppt}$ (NCAR) at $550 \mathrm{hPa}$, and continue to decrease at higher altitudes. However, elevated HCHO mixing ratios were observed on numerous occasions at altitudes above $500 \mathrm{hPa}$ over the eastern United States because of convection of boundary layer precursors, as discussed by Fried et al. (manuscript in preparation, 2006). Over the ocean, HCHO concentrations decrease from $540 \mathrm{ppt}$ (URI) to $880 \mathrm{ppt}$ (NCAR) near the surface to $120 \mathrm{ppt}$ (URI) to $230 \mathrm{ppt}$ (NCAR) at $550 \mathrm{hPa}$. The $30 \%$ offset between the NCAR and URI measurements is evident in the mean vertical distributions (Figure 2); for both the continental and oceanic subsets, the simulated mixing ratios fall within the range defined by the two sets of observations. The relative vertical distribution (shape factor), critical for our application, is also well simulated. Over the continent, measured and modeled ratios of the mean $\mathrm{HCHO}$ concentration at 960 versus $550 \mathrm{hPa}$ are 6.3 (NCAR), 8.0 (URI) and 7.8 (GEOS-Chem). The corresponding values over the ocean are 3.8 (NCAR), 4.3 (URI) and 3.7 (GEOS-Chem). Further analysis of shape factors in the context of the AMF calculation will be discussed below.

\subsection{Vertical Columns}

[23] We calculated $\mathrm{HCHO}$ vertical columns from observed and simulated $\mathrm{HCHO}$ mixing ratios during the DC8 vertical profiles. Extensive vertical profiling from the boundary layer $(\sim 300 \mathrm{~m}$ above surface) to the upper troposphere $(\sim 10 \mathrm{~km})$ was conducted during the mission. 


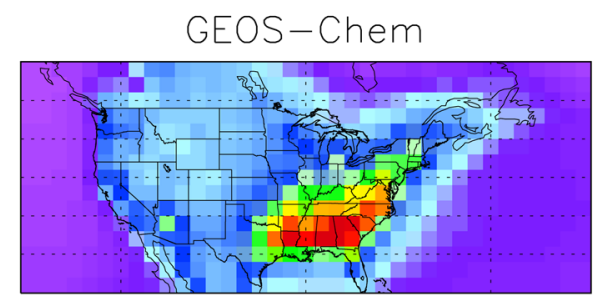

NCAR

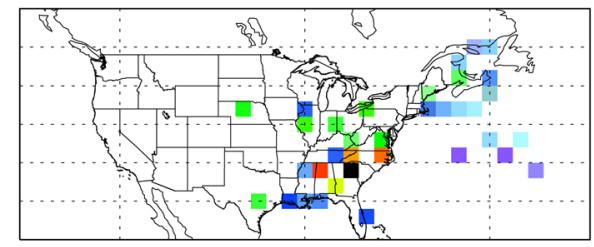

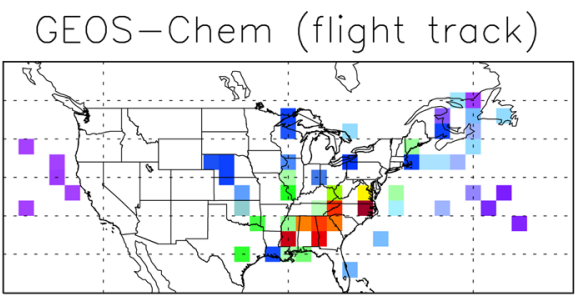

URI

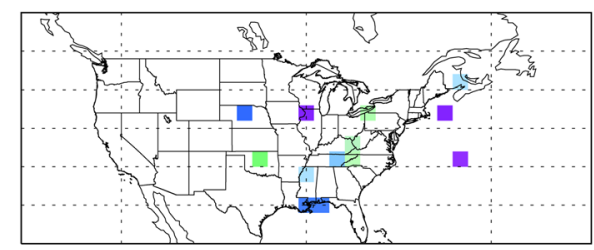

$\left[10^{16}\right.$ molecules $\left.\mathrm{cm}^{-2}\right]$

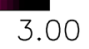

0.00

1.00

2.00

Figure 3. Atmospheric HCHO columns over North America. The top left plot shows GEOS-Chem
simulated columns averaged over the INTEX-A period (1 July to 15 August 2004). The other three plots show HCHO columns computed from HCHO mixing ratios measured (NCAR and URI) and simulated along the flight track during the DC-8 vertical profiles.

Here, we define as a vertical profile any flight segment meeting the following criteria: (1) observations extending from below $600 \mathrm{~m}$ (1000 $\mathrm{m}$ for marine profiles) to above $8 \mathrm{~km}$ radar altitude, (2) horizontal drift of less than $3^{\circ}$ latitude $\times 4^{\circ}$ longitude, and (3) at least 15 valid measurements. Mixing ratios above and below the profile were estimated by extending the values obtained at the highest and lowest altitudes uniformly to the tropopause and to Earth's surface. Mixing ratios in the stratosphere are negligible. Modeled columns calculated with these assumptions agree well with the corresponding model calculations for the full columns (slope $=0.97, \mathrm{R}^{2}=0.96$ ). We obtain in this manner 69 total profiles with a mean horizontal drift of $\sim 190 \mathrm{~km}$. Missing observations reduce the number of profiles to 36 for the NCAR HCHO data set and 13 for the URI HCHO data set.

[24] Figure 3 shows the resulting HCHO columns. Measured values range from 0.4 to $3.1 \times 10^{16}$ molecules $\mathrm{cm}^{-2}$ over continental North America, and from 0.4 to $0.8 \times$ $10^{16}$ molecules $\mathrm{cm}^{-2}$ over the ocean. Again, the bias between the two sets of measurements is manifest. Both modeled and measured columns are highest over the south- east United States, reflecting elevated isoprene emission [Lee et al., 1998] as discussed previously by Palmer et al. [2003]. Prior in situ observations have been too sparse to clearly define this maximum, but it is clearly revealed by the INTEX-A data. Scatterplots of simulated versus observed $\mathrm{HCHO}$ vertical columns are displayed in Figure 4. The model captures $70 \%$ of the variability in the observed NCAR columns, and $42 \%$ of that in the URI columns. The modeled HCHO columns have a bias (given by the slope of the regression line) of $+4 \%$ compared to NCAR and $+34 \%$ compared to URI.

\section{Relating HCHO Columns to Reactive VOC Emissions}

[25] In the following sections we use the data from the INTEX-A aircraft profiles to determine how column $\mathrm{HCHO}$ data from space can be interpreted in terms of the underlying reactive VOC emissions. Our first step is to determine which parent VOCs drive the variability in the $\mathrm{HCHO}$ column. For this purpose, we compute column integrated $\mathrm{HCHO}$ production rates from the precursor VOCs measured
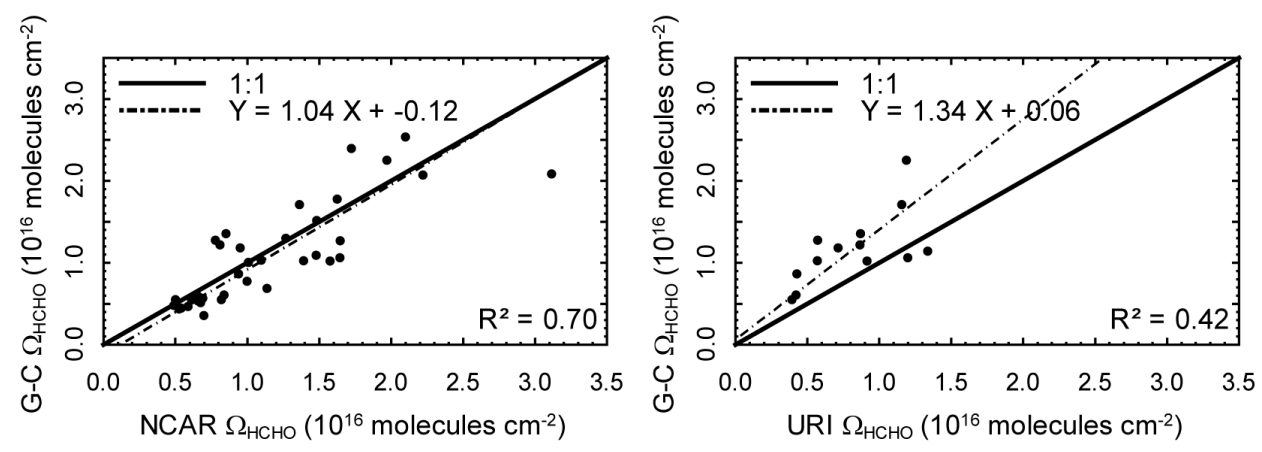

Figure 4. Scatterplots and reduced major axis regression of simulated (GEOS-Chem, G-C) versus observed HCHO columns during INTEX-A. 
Table 1. Formaldehyde Production Yields

\begin{tabular}{lc}
\hline \multicolumn{1}{c}{ Species } & Molar HCHO Yield \\
\hline Biogenics & \\
Isoprene & 2.3 \\
Alpha-pinene & $1.9^{\mathrm{b}}$ \\
Beta-pinene & $1.7^{\mathrm{b}}$ \\
Alkanes & \\
Methane & 1.0 \\
Ethane & 1.1 \\
Propane & 0.6 \\
בC4 alkanes & 2.0 \\
Alkenes & \\
Ethene & 1.8 \\
ZC3 alkenes & 2.0 \\
Aromatics & \\
Toluene & $1.2^{\mathrm{b}}$ \\
m-xylene & $2.1^{\mathrm{b}}$ \\
p-xylene & $2.0^{\mathrm{b}}$ \\
o-xylene & $2.2^{\mathrm{b}}$ \\
Ethylbenzene & $2.1^{\mathrm{c}}$ \\
C9 aromatics & $2.3^{\mathrm{c}}$ \\
Oxygenated VOCs (OVOCs) & \\
Acetone & 2.0 \\
Methanol & 1.0 \\
Ethanol & 1.0 \\
Acetaldehyde & 1.0 \\
\hline
\end{tabular}

${ }^{a}$ Yields are from the GEOS-Chem chemical mechanism (http://www. as.harvard.edu/chemistry/trop/geos/index.html) except where noted. See text for details.

${ }^{\mathrm{b}}$ From MCMv3.1 [Bloss et al., 2005; Palmer et al., 2006].

${ }^{c}$ Estimated assuming the same per-carbon yield as m-xylene.

aboard the aircraft and relate those to the measured $\mathrm{HCHO}$ columns. Here and for the remainder of the paper we restrict our analysis to the NCAR HCHO data set owing to its factor of $\sim 2$ higher data coverage.

[26] $\mathrm{HCHO}$ yields (high- $\mathrm{NO}_{\mathrm{x}}$ conditions) for all measured precursor VOCs with significant emissions are shown in Table 1. Yields and rates are obtained from the GEOS-Chem chemical mechanism, except where noted, and represent cumulative yields from the successive stages of oxidation of the parent compound until a product with a lifetime longer than a few hours is reached. The dependence of $\mathrm{HCHO}$ yields on $\mathrm{NO}_{\mathrm{x}}$ is discussed by Palmer et al. [2003, 2006]; low- $\mathrm{NO}_{\mathrm{x}}$ conditions leading to organic peroxide formation have little effect on ultimate yields if the organic peroxides decompose to regenerate radicals, as is commonly assumed, but the $\mathrm{HCHO}$ production is delayed.

[27] Column integrated $\mathrm{HCHO}$ production rates $\left(P_{\mathrm{HCHO}}\right.$, molecules $\mathrm{cm}^{-2} \mathrm{~s}^{-1}$ ) from $\mathrm{VOC}$ oxidation by $\mathrm{OH}$ were computed from the DC-8 vertical profiles for different classes of measured precursors using rate constant data from Sander et al. [2002] and Atkinson et al. [2004], HCHO yields from Table 1, and local $\mathrm{OH}$ concentrations from the GEOS-Chem model (Hudman et al., submitted manuscript, 2006). VOC vertical profiles were extrapolated below and above the aircraft in the same way as HCHO. Results for isoprene, oxygenated volatile organic compounds (OVOCs), anthropogenic nonmethane organic compounds (ANMHC), the monoterpenes $\alpha$ - and $\beta$-pinene, and methane are displayed as probability density functions in Figure 5 . The slant column fitting error for the satellite instrument $\left(4 \times 10^{15}\right.$ molecules $\mathrm{cm}^{-2}$ for GOME [Chance et al., 2000]), divided by the HCHO column lifetime ( $\sim 2$ hours), gives a lower limit for the magnitude of the $\mathrm{HCHO}$ source that can be detected from space $\left(\sim 0.6 \times 10^{12}\right.$ molecules $\left.\mathrm{cm}^{-2} \mathrm{~s}^{-1}\right)$. Methane and the OVOCs are ubiquitous in the atmosphere, and account for the majority of the total $\mathrm{HCHO}$ production. However, the variability in the resulting $\mathrm{HCHO}$ production is low (standard deviations of 0.3 and $0.2 \times 10^{12}$ molecules $\mathrm{cm}^{-2} \mathrm{~s}^{-1}$ ), and the column integrated $\mathrm{HCHO}$ production rate is always less than twice the nominal satellite detection limit of $0.6 \times$ $10^{12}$ molecules $\mathrm{cm}^{-2} \mathrm{~s}^{-1}$. These compounds therefore provide a HCHO column background over the study domain with no detectable variability. ANMHCs and monoterpenes are negligible under all conditions encountered during the vertical profiles. Column HCHO production from isoprene, on the other hand, with a variability (standard deviation $2.3 \times$ $10^{12}$ molecules $\mathrm{cm}^{-2} \mathrm{~s}^{-1}$ ) more than a factor of five greater than that due to any other VOC group, reaches levels well above the minimum level detectable from space. We conclude therefore that detectable variability in the $\mathrm{HCHO}$ column over North America in summer is driven primarily by isoprene emission, though with the caveat that the DC-8 sampling strategy did not include profiles directly over cities. While there were extensive boreal fires in Alaska and northern Canada during the study period [Pfister et al., 2005], because of the short HCHO lifetime they did not significantly impact the column integral $\mathrm{HCHO}$ during the vertical profiles.

[28] The HCHO column is strongly correlated $\left(\mathrm{R}^{2}=0.60\right)$ with $P_{\mathrm{HCHO}}$ from isoprene, and not with $P_{\mathrm{HCHO}}$ from other precursors (with the exception of monoterpenes). Even if isoprene were the sole source of $\mathrm{HCHO}$, the correlation between isoprene emissions and $\mathrm{HCHO}$ columns would still be degraded by the smearing effect of horizontal transport. The observed correlation is similar to that simulated by the GEOS-Chem model [Palmer et al., 2003]. While the HCHO column is also correlated with $\mathrm{HCHO}$ production from the monoterpenes $\alpha$ - and $\beta$-pinene $\left(R^{2}=0.65\right)$, the highest observed $P_{\mathrm{HCHO}}$ from these compounds is a factor of 10 less than the satellite detection limit of $0.6 \times 10^{12}$ molecules $\mathrm{cm}^{-2} \mathrm{~s}^{-1}$. The observed correlation is likely due to collocation of monoterpene and isoprene emissions. It has been suggested [Kurpius and Goldstein, 2003; Di Carlo et al., 2004; Goldstein et al., 2004; Holzinger et al., 2005] that reactive biogenic emissions from forests may include large amounts of unmeasured, possibly terpenoid, species. The reactivity-weighted abundance of these unmeasured compounds would have to be approximately 100 times greater than the sum of $\alpha$-plus $\beta$-pinene to generate values of $P_{\mathrm{HCHO}}$ comparable to those observed for isoprene, assuming comparable $\mathrm{HCHO}$ production yields. The fact that the simulated HCHO is in good agreement with the NCAR data (and is higher than the URI data), together with the fact that the distribution of HCHO columns over North America correlates with isoprene, not terpene, emission patterns [Palmer et al., 2006], indicates that any inherent bias in the approach due to unmeasured reactive terpenes is small.

[29] Figure 6 shows the relationship between observed $\mathrm{HCHO}$ columns and $P_{\mathrm{HCHO}}$ for the different precursors. Again we see that methane and the OVOCs give rise to a significant background $P_{\mathrm{HCHO}}$ of $\sim 1-1.5 \times 10^{12}$ molecules $\mathrm{cm}^{-2} \mathrm{~s}^{-1}$, but not to variability that that would be detectable from space. When the $\mathrm{HCHO}$ column exceeds the fitting uncertainty by a sufficient margin to provide a useful signal to the satellite instrument, changes are driven by isoprene. We conclude that space-borne measurements of $\mathrm{HCHO}$ 

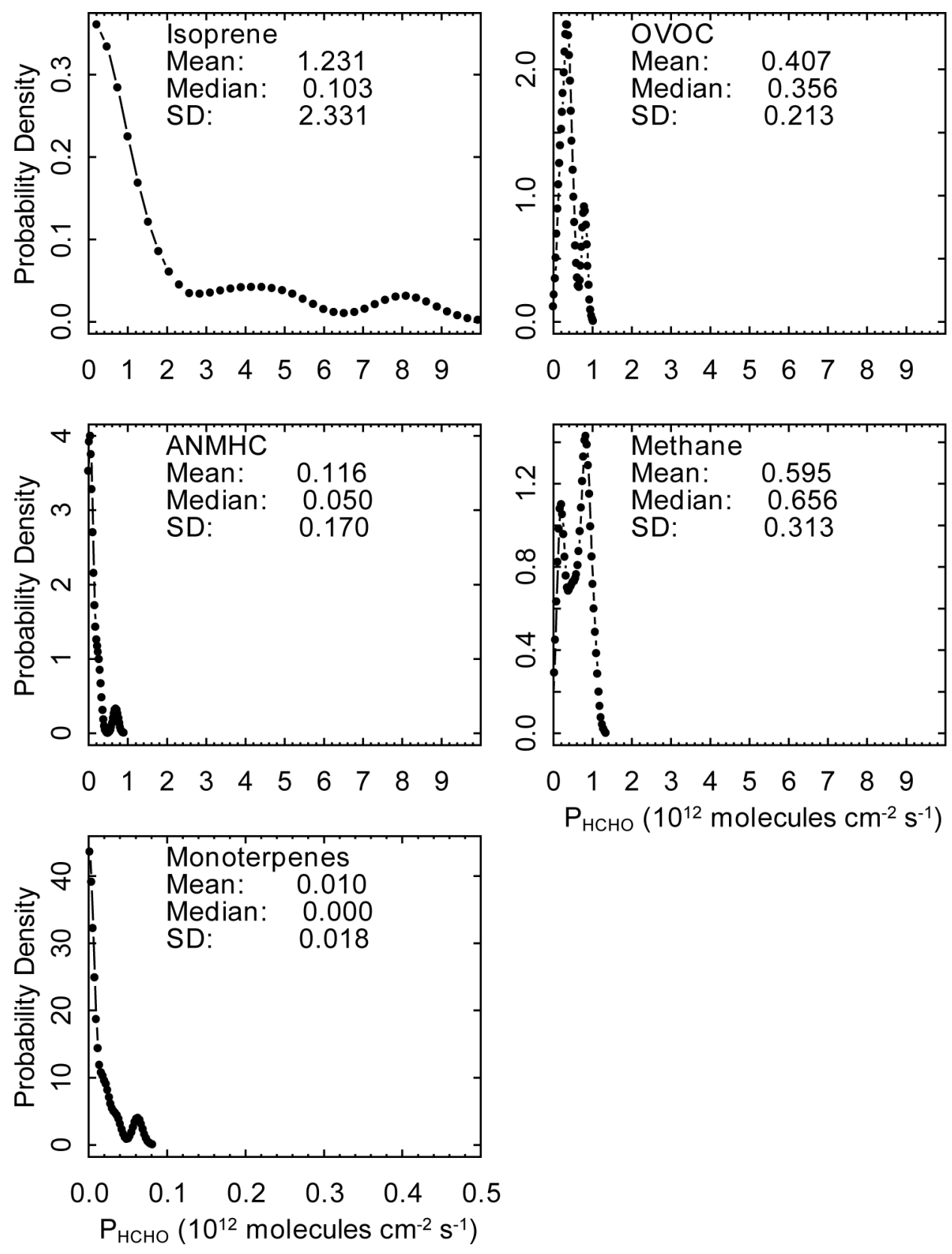

Figure 5. Probability density function of HCHO column production rates from different measured VOCs during INTEX-A vertical profiles: isoprene, oxygenated volatile organic compounds (OVOCs), anthropogenic nonmethane hydrocarbons (ANMHCs), methane, and monoterpenes. The dominant OVOCs for HCHO production are methanol and acetaldehyde, while the dominant ANMHCs are ethane, butane, and isopentane. Note the different $x$ axis scale in the fifth plot.

columns can reliably be used as a direct proxy for isoprene emissions over North America. This calculation provides an observational basis for previous studies, which have relied on modeled $\mathrm{HCHO}$-isoprene relationships.

\section{HCHO Yield From Isoprene}

[30] Using $\mathrm{HCHO}$ column data from space as a proxy for isoprene emission requires quantification of the relationship between the two. This has been done previously using GEOS-Chem model output [Palmer et al., 2003, 2006] and we use here the INTEX-A vertical profiles as a test of this approach. From equation (4), the slope of a linear regression of column $\mathrm{HCHO}\left(\Omega_{\mathrm{HCHO}}\right)$ versus column isoprene $\left(\Omega_{\text {ISOP }}\right)$, normalized by the ratio of the effective loss rate constants $k_{\mathrm{HCHO}}$ and $k_{\mathrm{ISOP}}$, represents the molar yield of $\mathrm{HCHO}$ production from isoprene oxidation. Figure $7 \mathrm{a}$ (black symbols) shows a scatterplot of modeled $k_{\mathrm{HCHO}} \Omega_{\mathrm{HCHO}}$ versus $k_{\mathrm{ISOP}} \Omega_{\mathrm{ISOP}}$, over the spatial domain encompassed by the continental and nearshore aircraft profiles $(27.82-$ $\left.49.80^{\circ} \mathrm{N} ; 59.81-98.96^{\circ} \mathrm{W}\right)$ and averaged over the INTEX-A timeframe. The reduced major axis slope, 1.84, is consistent 


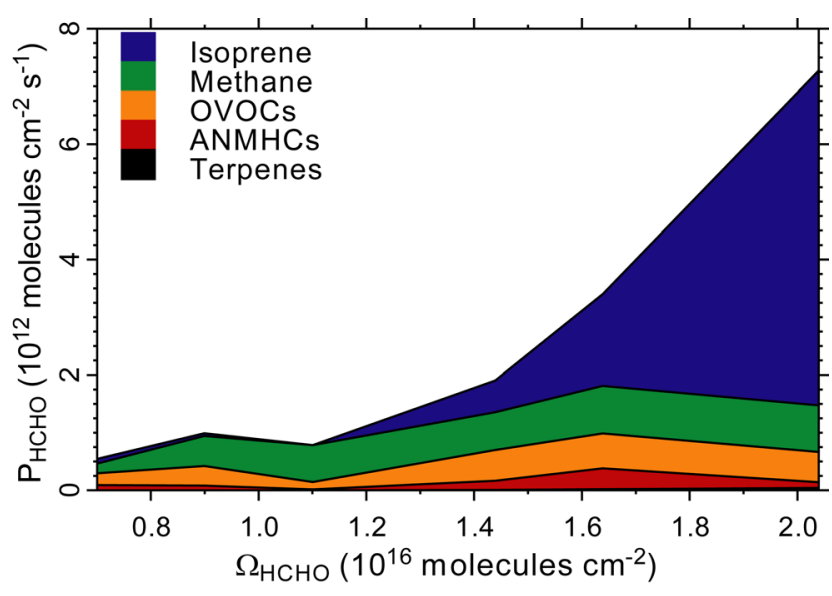

Figure 6. Stack plot showing the relationship between measured $\mathrm{HCHO}$ column $\left(\Omega_{\mathrm{HCHO}}\right)$ and $\mathrm{HCHO}$ production rate $\left(P_{\mathrm{HCHO}}\right)$ from different precursors. Isoprene is the dominant source of $\Omega_{\mathrm{HCHO}}$ variability.

with the nominal yield in Table 1 (2.3), given that the latter value assumes the high- $\mathrm{NO}_{\mathrm{x}}$ limit and that the integrated yield is a time-dependent quantity. Figure $7 \mathrm{~b}$ (black symbols) shows modeled $\Omega_{\mathrm{HCHO}}$ versus $\Omega_{\mathrm{ISOP}}$ for the same region and time frame, with a slope of 3.99. The ratio of the slopes from the two plots (2.2) corresponds to the mean ratio $k_{\mathrm{ISOP}} / k_{\mathrm{HCHO}}$

[31] Plots of $\Omega_{\mathrm{HCHO}}$ versus $\Omega_{\mathrm{ISOP}}$ calculated from concentrations measured aboard the DC- 8 aircraft or simulated along the flight track during the continental and nearshore vertical profiles are shown in Figures $7 \mathrm{~b}$ (model, red symbols) and $7 \mathrm{c}$ (measurements). Using the model value $k_{\mathrm{ISOP}} / k_{\mathrm{HCHO}}=2.2$, which should be reliable (errors in model $\mathrm{OH}$ partly cancel in the ratio), the observed $\Omega_{\mathrm{HCHO}}-\Omega_{\mathrm{ISOP}}$ slope implies an average molar $\mathrm{HCHO}$ yield from isoprene oxidation of $1.63 \pm 0.26$, compared to the modeled value of $1.66 \pm 0.27$. Uncertainties reflect the standard error of the regression. Error estimates computed using jackknife resampling are slightly higher $(0.33$ and 0.52 for the modeled and measured values, respectively). We conclude from the INTEX-A data that the GEOS-Chem HCHO yield from isoprene oxidation is correct to within $30 \%$.

\section{Uncertainty in the Air Mass Factor \\ 7.1. AMF Simulation}

[32] In this section we employ the extensive mapping of $\mathrm{HCHO}$ over North America from the INTEX-A mission to quantify the uncertainties and bias in the AMF calculation. To do so, we calculate air mass factors separately on the
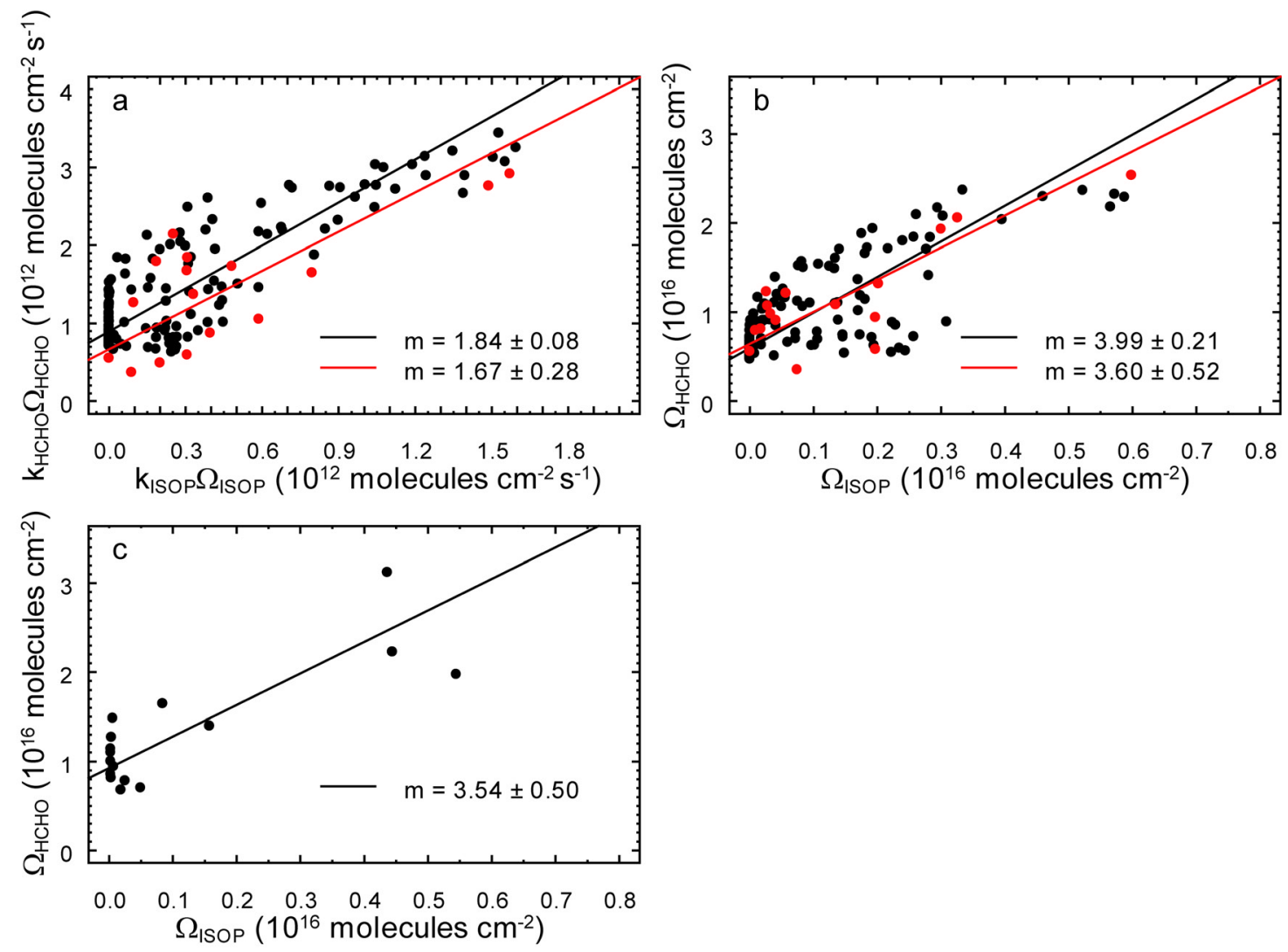

Figure 7. (a and b) Simulated and (c) observed relationships between HCHO and isoprene columns. Figure $7 \mathrm{a}$ shows modeled $k_{\mathrm{HCHO}} \Omega_{\mathrm{HCHO}}$ versus $k_{\mathrm{ISOP}} \Omega_{\mathrm{ISOP}}$ averaged over the INTEX-A spatial and temporal domain (black), and for the locations and times corresponding to the DC-8 vertical profiles (red). Figure $7 \mathrm{~b}$ shows modeled $\Omega_{\mathrm{HCHO}}$ versus $\Omega_{\mathrm{ISOP}}$ with the same color scheme. Figure $7 \mathrm{c}$ shows $\Omega_{\mathrm{HCHO}}$ versus $\Omega_{\mathrm{ISOP}}$ calculated from concentrations measured aboard the aircraft during the profiles. The observed $\Omega_{\mathrm{HCHO}}-\Omega_{\mathrm{ISOP}}$ slope indicates an average molar HCHO yield from isoprene oxidation of 1.6. 


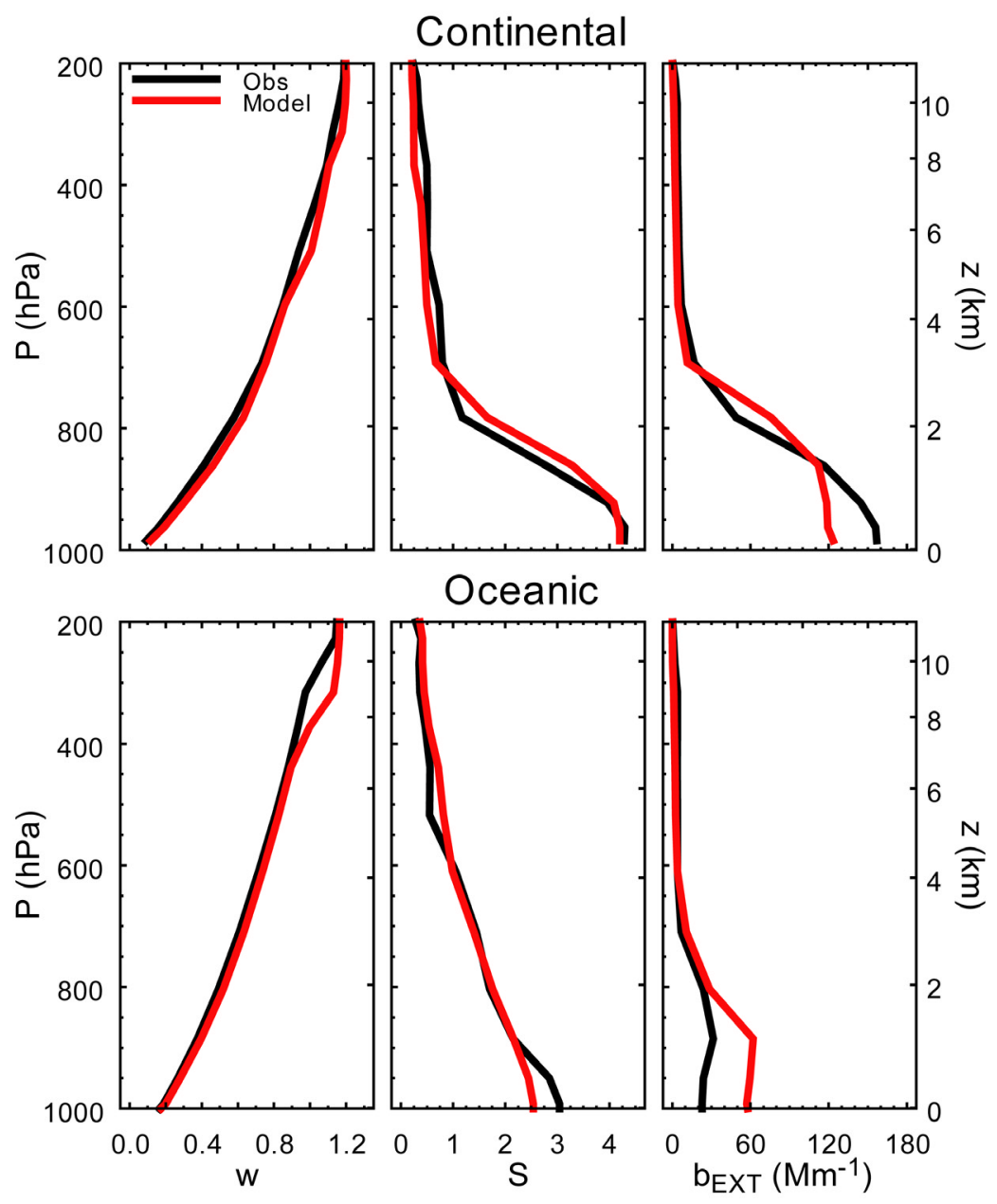

Figure 8. Measured (black) and modeled (red) vertical profiles of satellite instrument sensitivity (scattering weights, $w$ ), normalized $\mathrm{HCHO}$ concentration (shape factor, $S$ ), and aerosol extinction $\left(b_{E X T}\right.$, $\mathrm{Mm}^{-1}$ ), averaged over the DC-8 continental and oceanic vertical profiles during INTEX-A.

basis of measurements and on the basis of model results, for each of the DC-8 vertical profiles during INTEX-A. Assuming that the measurements perfectly represent the atmosphere, the comparison statistics between the measured and modeled AMFs give a measure of the corresponding error in retrieved satellite $\mathrm{HCHO}$ vertical columns.

[33] Measured and modeled air mass factors were calculated from equation (2) for a nadir viewing geometry. Shape factors, $S(P)$, were determined using either measured or modeled $\mathrm{HCHO}$ mixing ratios. Extrapolation of mixing ratios above and below the profile was done in the same way as for the column estimates (section 4.2). Measured and modeled shape factors averaged over all the continental and oceanic vertical profiles are displayed in Figure 8. The GEOS-Chem model accurately captures the mean shape of the vertical profile, including the steep drop-off above the continental boundary layer.

[34] Scattering weights, $w(P)$, for each profile were computed using the Linearized Discrete Ordinate Radiative Transfer (LIDORT) model [Spurr et al., 2001], and include scattering by air molecules, aerosols and clouds. Surface UV albedos are from a climatological database based on GOME observations [Koelemeijer et al., 2003]. Aerosol effects on the measured AMF values were accounted for using local aerosol scattering and absorption measured at 10-60 s resolution aboard the aircraft (A. Clarke et al., Biomass burning and pollution aerosol over North America: Organic components and their influence on spectral optical properties and humidification response, submitted to Journal of Geophysical Research, 2006; Y. Shinozuka et al., Aircraft profiles of aerosol microphysics and optical properties over North America: Aerosol optical depth and its association with PM2.5 and water uptake, submitted to Journal of Geophysical Research, 2006). The median single scattering albedo at $346 \mathrm{~nm}$ during the aircraft profiles is 0.88 (0.1-0.9 quantiles: 0.76-0.97). However, the aerosols encountered near the surface $(\mathrm{P}>800 \mathrm{hPa})$, where the majority of the aerosol (and $\mathrm{HCHO}$ ) column resides, were predominantly scattering (median single scattering albedo 0.97). The measured aerosol absorption coefficient has a large percentage of missing values, which we fill in by applying the mean single-scattering albedo to the measured scattering coefficient. Integrating the measured aerosol extinction over the individual vertical profiles yields aerosol optical thicknesses (AOTs) at $346 \mathrm{~nm}$ ranging from 0.05 to 0.83 , with a mean of 0.26 (Figure 9). The corresponding modeled AOTs computed from GEOS-Chem and used in the modeled AMF calculation range from a minimum of 
Measured Aerosol OT Modeled Aerosol OT
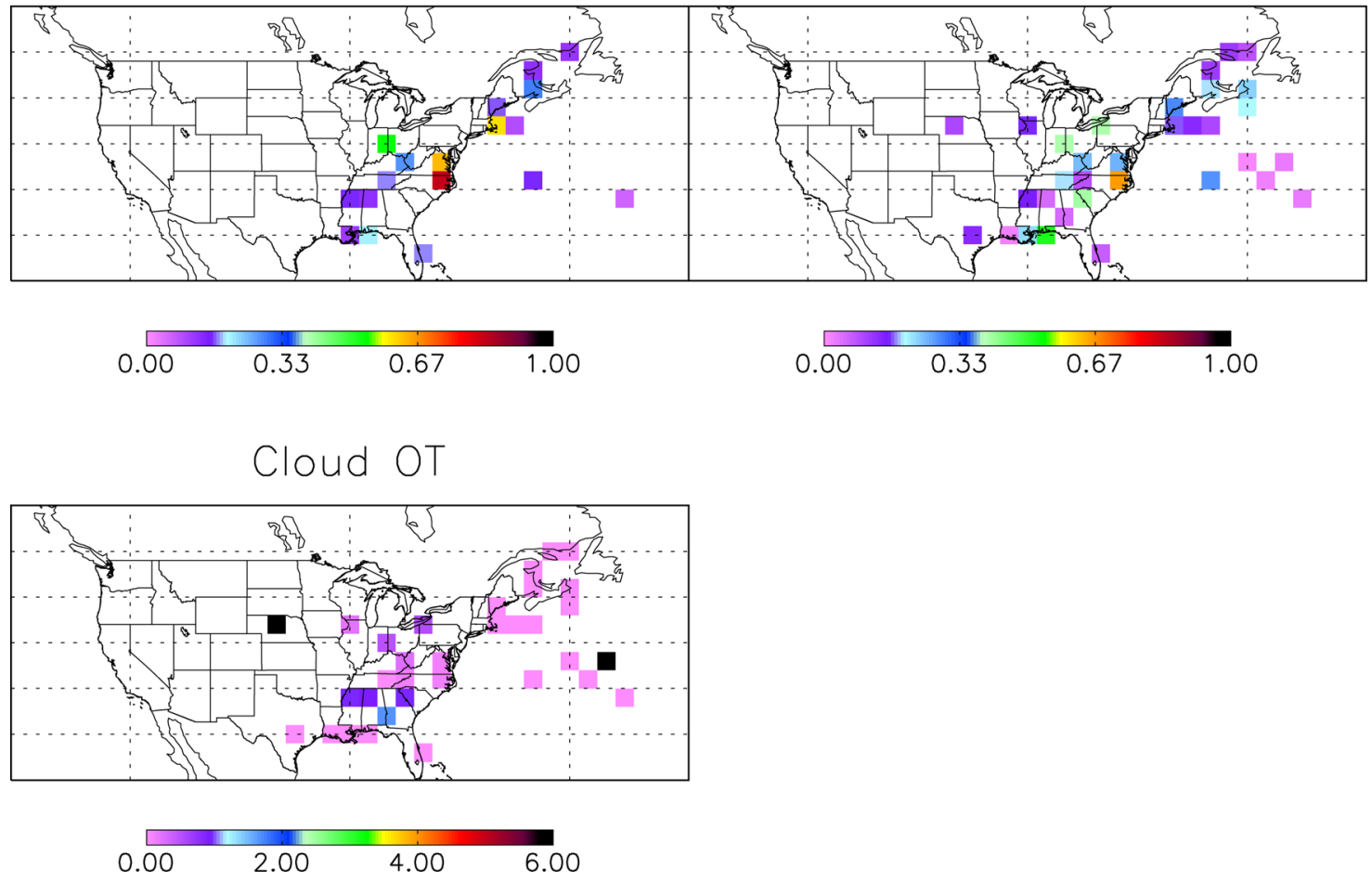

Figure 9. Measured and modeled column aerosol optical thickness, and measured cloud optical thickness, for the INTEX-A vertical profiles.

0.03 to a maximum of 0.66 with a mean of 0.22 (Figure 9). A reduced major axis regression of the modeled versus measured AOTs yields a slope of 0.73 , and a coefficient of determination $\left(\mathrm{R}^{2}\right)$ of 0.41 . The model reproduces the general vertical shape of the measured aerosol extinction, in particular the sharp decrease above the continental boundary layer which is similar to that observed for $\mathrm{HCHO}$ (Figure 8). However, the modeled extinction is biased high in the marine boundary layer and biased low in the continental boundary layer.

[35] The impact of clouds on the measured AMFs was included using in situ cloud extinction measurements made during the vertical profiles, as shown in Figure 9. Only 16 of the profiles have cloud optical thicknesses greater than unity because the DC- 8 flight strategy favored clear-sky profiling. For the modeled AMF, we assume that there is accurate information available regarding the cloud top height and optical thickness, since those parameters can be retrieved from satellite instruments such as GOME [Martin et al., 2002a]. Koelemeijer et al. [2001], comparing two different cloud retrieval schemes for GOME, report average differences of 0.04 and $65 \mathrm{hPa}$ for cloud fraction and cloud top pressure. Comparing four cloud fraction retrievals along four GOME tracks, Tuinder et al. [2004] found the mean difference between products to range from 2 to $25 \%$. Here we take the cloud top and total optical thickness information from the aircraft cloud extinction data, and distribute the cloud optical thickness vertically below cloud top following Martin et al. [2002a] by assuming an optical thickness of 8 per $100 \mathrm{hPa}$ of cloud. The cloud top height is taken as the maximum altitude above which the cloud optical thickness is greater than unity (detection limit from GOME; T. P. Kurosu, personal communication, 2005). Profiles having an integrated cloud optical thickness less than one were treated as being cloud-free for the modeled AMF calculation, but not for the measured AMF calculation.

[36] The resulting mean vertical profiles of scattering weights $w(P)$ are shown in Figure 8 for continental and oceanic scenes. The vertical distribution reflects the increasing sensitivity of the satellite instrument with altitude, and deviates from a smooth curve because of cloud and aerosol scattering. As we see, model assumptions regarding aerosols and clouds do not incur significant error in the mean $w(P)$ profile, although this could reflect the prevalence of clear-sky scenes. A more specific assessment of the error for cloudy scenes is presented below.

[37] Measured and modeled AMFs for the ensemble of INTEX-A vertical profiles are mapped in Figure 10 and compared in Figure 11. A reduced major axis regression of the modeled versus measured AMF gives a slope of 0.78 and an $\mathrm{R}^{2}$ of 0.45 (Figure 11). This includes all clear and cloudy profiles. As the overall AMF for a partly cloudy scene is given by a weighted average of the clear and cloudy values (equation (3)), we can assess the errors in $\mathrm{AMF}_{\text {clear }}$ and $\mathrm{AMF}_{\text {cloud }}$ separately using the clear and cloudy profiles, and that in the overall AMF as a function of the cloud fraction $f$. In what follows, AMF comparisons are given in terms of harmonic means, since the dependence of the $\mathrm{HCHO}$ vertical column on the slant column is defined by the inverse of the AMF. Biases in the modeled AMF are calculated as $\left(\mathrm{AMF}_{\text {mod }}-\mathrm{AMF}_{\text {meas }}\right) / \max \left(\mathrm{AMF}_{\text {mod }}, \mathrm{AMF}_{\text {meas }}\right)$; the $\mathrm{AMF}$ 

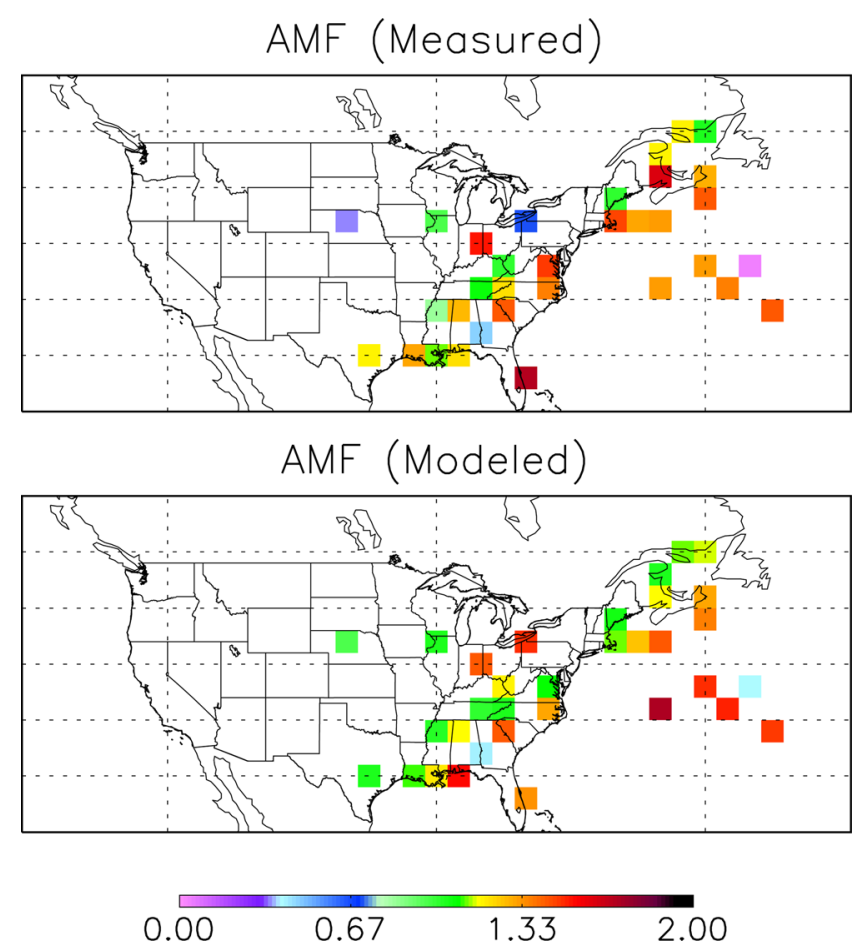

Figure 10. Measured and modeled HCHO air mass factors for the DC-8 vertical profiles during INTEX-A.

bias is opposite in sign to the resulting effect on the retrieved HCHO vertical column.

\section{2. $\mathbf{A M F}$ clear}

[38] For all clear-sky profiles $(\mathrm{N}=31)$, the measured and modeled AMFs range from 0.72 to 1.69 and from 1.00 to 1.71, respectively (Figure 11 and Table 2). The harmonic means (1.21 and 1.23) are identical to within one standard error. The mean bias in the modeled AMF is less than $1 \%$; the standard deviation of the bias, which gives a measure of the precision of the retrieval, is $17 \%$. To the extent that the model error is random, the uncertainty in time-averaged vertical profiles of $\mathrm{HCHO}$ will decrease with increasing observations.

[39] The AMF uncertainty for continental profiles under clear-sky conditions is comparable to that for the entire data set (SD of the bias: 18\%), while that for oceanic profiles is lower (SD of the bias: 10\%). The mean bias in the modeled $\mathrm{AMF}$ is $-2 \%$ (SE: $4 \%$ ) over the continent, and $+7 \%$ (SE: $4 \%$ ) over the ocean.

\section{3. $\mathbf{A M F}_{\text {cloud }}$}

[40] Of the 69 aircraft profiles, 16 have cloudy skies (cloud optical thickness greater than one). Of these, only 3 have a sufficient number of $\mathrm{HCHO}$ and aerosol extinction measurements to compute air mass factors. In order to make the best use of the available data, and in view of the importance of determining cloud effects, we calculated cloudy AMFs by applying the 16 cloud profiles to each of the 34 vertical profiles with adequate $\mathrm{HCHO}$ and aerosol data. This gives 544 values of $\mathrm{AMF}_{\text {cloud }}$ (Figure 11 and Table 2). The measured and modeled distributions of $\mathrm{AMF}_{\text {cloud }}$ show two distinct modes, the first at AMF values less than one and the second at values greater than one
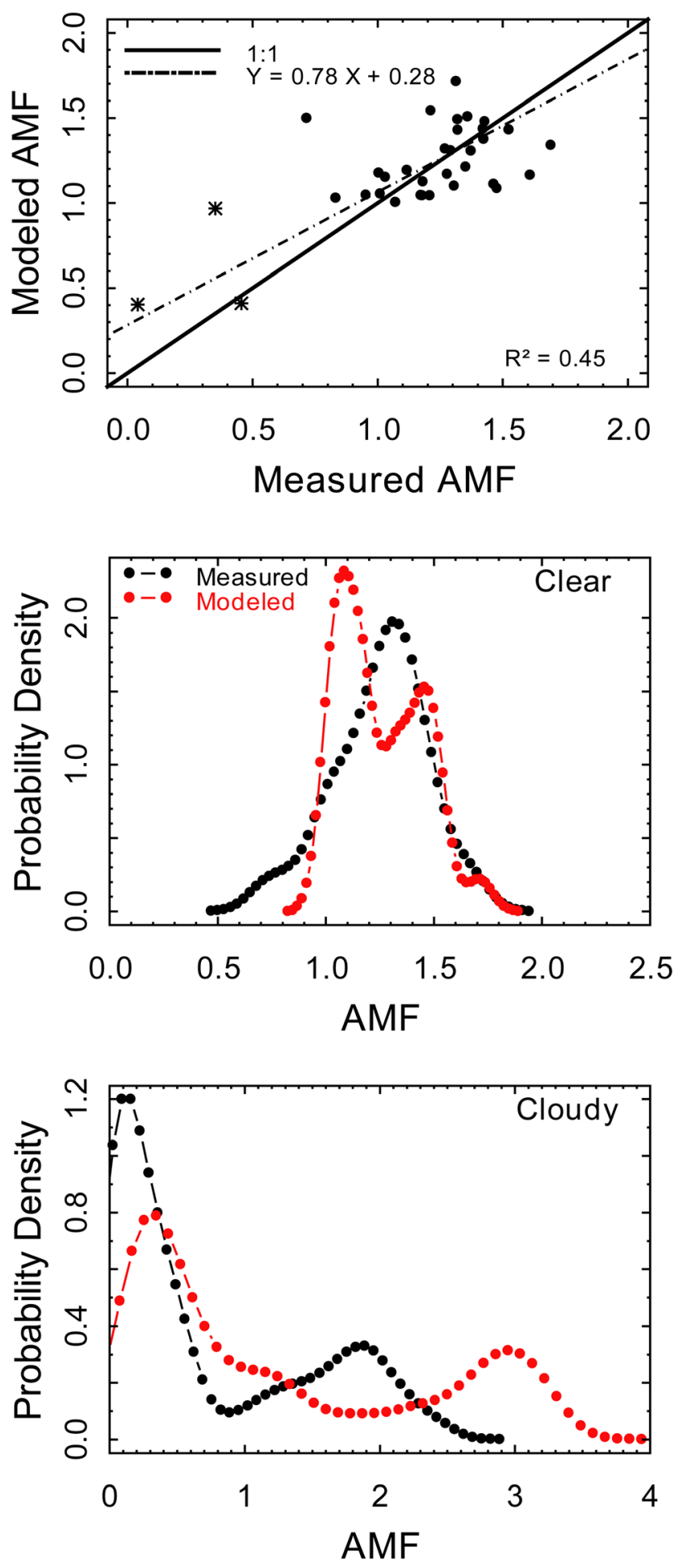

Figure 11. (top) Scatterplot of modeled versus measured air mass factors computed for the DC-8 vertical profiles. Clear-sky and cloudy profiles are represented by points and asterisks, respectively. Probability density functions of (middle) $\mathrm{AMF}_{\text {clear }}$ and (bottom) $\mathrm{AMF}_{\text {cloud. }}$ The pdf of $\mathrm{AMF}_{\text {cloud }}$ is based on 544 data points as described in the text. 
Table 2. AMF Comparison Statistics

\begin{tabular}{|c|c|c|c|c|c|}
\hline & \multirow[b]{2}{*}{$\mathrm{N}$} & \multicolumn{2}{|l|}{ AMF } & \multicolumn{2}{|c|}{ Model Bias, \% } \\
\hline & & Harmonic Mean & SD & Mean & $\mathrm{SD}$ \\
\hline \multicolumn{6}{|c|}{$A M F_{\text {clear }}$} \\
\hline \multicolumn{6}{|l|}{ All profiles } \\
\hline Measured & 31 & 1.21 & 0.22 & - & - \\
\hline Modeled & 31 & 1.23 & 0.19 & $0 \%$ & $17 \%$ \\
\hline \multicolumn{6}{|c|}{ Continental and nearshore profiles } \\
\hline Measured & 24 & 1.18 & 0.24 & - & - \\
\hline Modeled & 24 & 1.18 & 0.16 & $-2 \%$ & $18 \%$ \\
\hline \multicolumn{6}{|c|}{ Oceanic profiles } \\
\hline Measured & 7 & 1.34 & 0.05 & - & - \\
\hline Modeled & 7 & 1.43 & 0.16 & $+7 \%$ & $10 \%$ \\
\hline \multicolumn{6}{|c|}{$A M F_{\text {cloud }}$} \\
\hline Measured & $544^{\mathrm{b}}$ & $0.13^{\mathrm{c}}$ & 0.75 & - & - \\
\hline Modeled & $544^{\mathrm{b}}$ & $0.44^{\mathrm{c}}$ & 1.08 & $+46 \%$ & 39 \\
\hline
\end{tabular}

${ }^{a}$ Measured and modeled AMFs calculated from in situ measurements and chemical transport model results for each of the DC-8 vertical profiles during INTEX-A.

${ }^{\mathrm{b}}$ For each of the 34 vertical profiles with adequate data coverage, values of $\mathrm{AMF}_{\text {cloud }}$ were calculated using all of the 16 cloud profiles encountered during the entire study.

${ }^{\mathrm{c}}$ The harmonic mean for $\mathrm{AMF}_{\text {cloud }}$ is skewed by values close to zero. The median measured and modeled values are 0.35 and 0.76 , respectively.

(Figure 11). This reflects the tendency of low clouds to increase the measurement sensitivity, and of high clouds to decrease the sensitivity. The mean bias in the modeled $\mathrm{AMF}_{\text {cloud }}$ is $+46 \%$ (compared to $<1 \%$ for $\mathrm{AMF}_{\text {clear }}$ ), and the standard deviation of the bias is $39 \%$ (compared to $17 \%$ for $\mathrm{AMF}_{\text {clear }}$ ). Clouds are therefore the largest source of error in the AMF calculation.

\subsection{AMF for Partly Cloudy Scenes}

[41] A useful parameter for the satellite retrieval is the cloud fraction above which the AMF error becomes unacceptably large. Here, we employ the 544 measured values of $\mathrm{AMF}_{\text {cloud }}$ to derive a measure of the AMF error as a function of the cloud fraction of the retrieval scene. The weighted average AMF was calculated from equation (3) for cloud fractions ranging from zero to one. Figure 12 shows the bias and the standard deviation of the bias in the modeled AMF as a function of the cloud fraction of the scene. The mean bias from the 544 partly cloudy AMF calculations (solid black line in Figure 12) is $10 \%, 14 \%$, $17 \%$, and $21 \%$ at cloud fractions of $30 \%, 40 \%, 50 \%$ and $60 \%$. The standard deviation in the bias reflects the precision in the AMF calculation, with values of $19 \%, 21 \%$, $23 \%$, and $25 \%$ at cloud fractions of $30 \%, 40 \%, 50 \%$ and $60 \%$ (red line in Figure 12). On the basis of this result, we recommend discarding scenes with $50 \%$ cloud coverage or more. This does not include uncertainty arising from the surface albedo, which is considered separately below.

[42] In addition to clouds, the other potentially important sources of model uncertainty in the AMF calculation are the shape factor, aerosols, and the surface albedo. In order to identify potential areas for improvement in the AMF calculation, the effects of these are assessed individually using sensitivity calculations described below.

\subsection{Surface Albedo}

[43] Surface albedos for AMF calculations may be obtained from climatological databases derived from satellite measurements [Martin et al., 2003a; Beirle et al., 2004;
Boersma et al., 2004; Martin et al., 2004; Konovalov et al., 2005; Palmer et al., 2006]. The precision of the surface albedo database derived from GOME spectra is estimated at 0.02 [Koelemeijer et al., 2003]. We assessed the resulting error in the $\mathrm{HCHO}$ air mass factor by recalculating the modeled clear-sky AMFs with the UV albedos uniformly increased and decreased by 0.02 . The resulting AMF values have a mean bias of $+5 \%$ in the first case, and $-5 \%$ in the second. We therefore estimate the $1 \sigma$ uncertainty introduced by the surface albedo at $5 \%$.

[44] Adding this quantity in quadrature to the standard deviation of the AMF bias calculated above as a function of cloud fraction, results in an overall $1 \sigma$ uncertainty due to the AMF which increases from $15 \%$ for clear skies, to $18 \%$, $20 \%, 22 \%$, and $24 \%$ at $f=0.2,0.3,0.4$, and 0.5 .

\subsection{Aerosols}

[45] In order to examine the importance of aerosols for the AMF calculation, and the extent to which the GEOSChem model captures this effect, the measured and modeled AMFs were calculated for each vertical profile assuming aerosol-free conditions. For the purposes of this aerosol sensitivity study, we use the 19 out of 34 profiles where the aerosol absorption was measured rather than estimated. On average, the presence of aerosols increases the measured AMF by $14 \%$ relative to the aerosol-free scenario. The effect is substantially larger over the North American continent ( $16 \%$ increase) than over the ocean ( $2 \%$ increase) because of higher aerosol loadings (mean column optical thickness of 0.3 versus 0.1 ). The modeled AMF using the GEOS-Chem aerosol profile information also shows a positive sensitivity to aerosols, somewhat stronger than observations ( $22 \%$ over continents, $10 \%$ over the ocean).

\subsection{Shape Factor}

[46] Errors introduced in the AMF because of the use of the modeled $\mathrm{HCHO}$ shape factor were assessed by using the

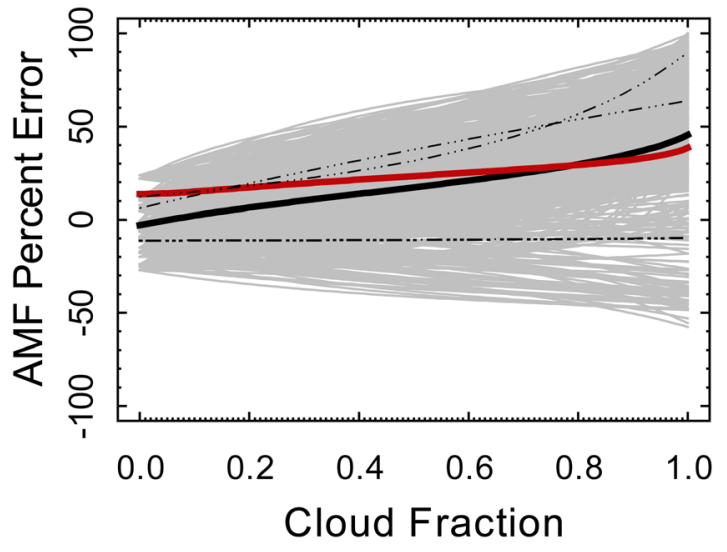

Figure 12. Error in the modeled AMF as a function of the cloud fraction. Black dot-dashed lines show data for the three actual INTEX-A profiles having integrated cloud optical thickness greater than unity together with sufficient $\mathrm{HCHO}$ and aerosol data coverage. The grey lines show the errors for the 544 profiles sampled as described in the text. The solid black line shows the mean bias for these 544 calculations, and the red line shows the standard deviation in the bias. 
measured $\mathrm{HCHO}$ vertical profile in the calculation of the modeled AMF. In the mean, errors in the model shape factor change the bias in the modeled AMF from $+5 \%$ to $-2 \%$ over the continent and from $+3 \%$ to $+7 \%$ over the ocean. Over the continent, the positive bias induced in the AMF by the modeled aerosol $(+5 \%)$ is therefore masked by the negative bias induced by the modeled shape factor $(-7 \%)$.

\subsection{AMF Variability}

[47] Using CTM simulations of HCHO vertical profiles for individual scenes to calculate AMFs ensures consistency when comparing the resulting observed vertical columns to those simulated by the same CTM. For the more general purpose of displaying observed vertical columns, however, there is advantage to using a single representative $\mathrm{HCHO}$ profile, since this ensures that variability in the observations is real and not introduced by the model.

[48] Overall, the modeled AMF captures $45 \%$ of the variability in the measured AMF (Figure 11). This is mostly driven by cloud scenes. The variability in the clear-sky $\mathrm{AMF}$ is low (relative standard deviation, $\mathrm{RSD},=0.15$ ), which indicates that factors such as mixing height do not introduce significant variability into the AMF. The coefficient of determination between the inverse of the measured and modeled AMFs increases with cloud fraction to $\mathrm{R}^{2}\left(\mathrm{AMF}_{\text {meas }}^{-1}, \mathrm{AMF}_{\text {mod }}^{-1}\right)=0.61$ at $f=0.5$. The noise that is introduced in the retrieved columns from the modeled $\mathrm{AMF}$, given by $\left(1-\mathrm{R}^{2}\left(\mathrm{AMF}_{\text {meas }}^{-1}, \mathrm{AMF}_{\mathrm{mod}}^{-1}\right)\right) *$ $\mathrm{RSD}\left(\mathrm{AMF}_{\mathrm{mod}}^{-1}\right)$, increases from 0.12 at $f=0$ to 0.17 at $f=0.5$.

\section{Conclusions}

[49] We used extensive aircraft vertical profiling over North America during the INTEX-A mission in summer 2004 to quantify the errors in retrieving and interpreting $\mathrm{HCHO}$ column data from space. By correlating the aircraft observations of $\mathrm{HCHO}$ columns with the column $\mathrm{HCHO}$ production rates inferred from concurrent VOC measurements, we showed that variability in the $\mathrm{HCHO}$ column over North America in summer is mainly determined by isoprene emission. For the ensemble of the INTEX-A profiles, none of the other VOCs contributed to $\mathrm{HCHO}$ at a level that would be detected from space, with the caveat that the DC-8 sampling strategy did not include profiles directly over cities. Satellite retrievals of HCHO columns can therefore be used reliably as a proxy for isoprene emissions over North America. In addition to providing independent constraints on emission inventories, these data offer the opportunity to examine the sensitivity of isoprene emissions to environmental drivers, assess the magnitude and implications of interannual variability in biogenic emissions [Abbot et al., 2003; Palmer et al., 2006], and study the effects of human influences such as logging and land use change on emissions of isoprene.

[50] Relating $\mathrm{HCHO}$ columns to isoprene emissions requires accurate knowledge of the yield of $\mathrm{HCHO}$ from isoprene oxidation. From correlation of measured $\mathrm{HCHO}$ and isoprene columns measured from the aircraft, we estimate a molar HCHO yield of $1.6 \pm 0.5$. This value is consistent with current chemical mechanisms used in CTMs, and in particular in the GEOS-Chem CTM used in past interpretation of GOME HCHO column data. The observed correlation between $\mathrm{HCHO}$ and isoprene columns has an $\mathrm{R}^{2}$ of 0.60 , again consistent with GEOS-Chem and indicating some horizontal smearing due to the time lag between isoprene emission and $\mathrm{HCHO}$ production.

[51] The primary source of error in $\mathrm{HCHO}$ satellite retrievals is the air mass factor (AMF), which defines the relationship between measured radiances and $\mathrm{HCHO}$ vertical columns. The standard approach for computing the AMF is to use local vertical profile information from a CTM, and we have used GEOS-Chem for this purpose in the past. Here we compared the AMFs calculated from the observed vertical profiles of $\mathrm{HCHO}$, aerosol extinction, and cloud extinction to those calculated using GEOS-Chem model HCHO and aerosol profiles combined with the cloud information one would expect to get from space (cloud top and total optical thickness). Aerosols increase the AMF over North America by $16 \%$ on average and are thus important to include in the AMF calculation.

[52] Our analysis shows that clouds are the main source of error in the model AMF calculation. The mean bias in the model AMF increases from $<1 \%$ under clear-sky conditions to $17 \%$ under $50 \%$ cloudy conditions. The residual $1 \sigma$ error (after subtraction of the mean bias) is $15 \%$ under clear-sky conditions and $24 \%$ under $50 \%$ cloudy conditions. The UV surface albedo used in our AMF calculation results in an AMF uncertainty of $\pm 5 \%$. Combining these quantities in quadrature with a fitting uncertainty of $4 \times 10^{15}$ molecules $\mathrm{cm}^{-2}$, we arrive at an overall $1 \sigma$ uncertainty in retrieved $\mathrm{HCHO}$ vertical columns which increases from $25 \%$ at $f=0$ to $31 \%$ at $f=0.5$, for a slant column of $2 \times 10^{16}$ molecules $\mathrm{cm}^{-2}$. We recommend discarding retrieval scenes with greater than $50 \%$ cloud cover. The fraction of the total data coverage this represents will depend on the size of the satellite footprint; GOME scenes with $>40 \%$ cloud cover represent approximately $40 \%$ of the data coverage over North America in summer [Abbot et al., 2003].

[53] In the absence of clouds, AMF variability is low $(\mathrm{RSD}=0.15)$. We find that the artificial variability that is introduced in $\mathrm{HCHO}$ column retrievals from the use of AMFs modeled using the GEOS-Chem CTM is $12-17 \%$ when the cloud fraction is less than 0.5 .

[54] How accurately we can infer isoprene emissions from $\mathrm{HCHO}$ column measurements made from space depends on the retrieval errors, as well as uncertainties in the $\mathrm{HCHO}$ yield, errors in the $\mathrm{HCHO}$ loss rate, and uncertainties associated with converting the $\mathrm{HCHO}$ column at the satellite overpass time to a diurnal average. Modeled $\mathrm{HCHO}$ yields from isoprene oxidation can differ by $30 \%$ between models at a given $\mathrm{NO}_{\mathrm{x}}$ level [Palmer et al., 2006], with differences highest at low $\mathrm{NO}_{\mathrm{x}}$. The $\mathrm{HCHO}$ yield calculated in the present work also has an estimated uncertainty of $30 \%$. Errors associated with the HCHO loss rate and diurnal cycle are likely to be minor in comparison. The uncertainty in the $\mathrm{HCHO}$ production yield, combined in quadrature with the retrieval errors calculated above, results in a $1 \sigma$ uncertainty in isoprene emissions derived from satellite measurements of $\mathrm{HCHO}$ columns of $39-43 \%$ (again for a slant column abundance of $2 \times 10^{16}$ molecules $\mathrm{cm}^{-2}$ ). This level of uncertainty compares favorably to that associated with extrapolating leaf and plant-level emission data [Guenther et al., 2000]. The overall approach therefore 
offers a useful and independent means of inferring surface emissions of isoprene.

[55] In other parts of the world, processes such as biomass burning [Thomas et al., 1998; Burrows et al., 1999; Spichtinger et al., 2004; Meyer-Arnek et al., 2005] and anthropogenic emissions (T.-M. Fu et al., manuscript in preparation, 2006) can also make significant and detectable contributions to column HCHO. New satellite instruments such as OMI, aboard Aura, and GOME-2, to be launched aboard the MetOp satellites, should enable mapping of biogenic, urban and biomass burning VOC emissions with much improved spatial and temporal coverage compared to GOME. The results presented here offer a foundation for future such analyses.

[56] Acknowledgments. Financial support for this research was provided by the NASA Atmospheric Chemistry Modeling and Analysis Program and by the NOAA Climate and Global Change Postdoctoral Fellowship Program (DBM). The authors thank Bob Yantosca, Paul Palmer, and Thomas Kurosu for their help and the entire INTEX-A science team for their efforts.

\section{References}

Abbot, D. S., P. I. Palmer, R. V. Martin, K. V. Chance, D. J. Jacob, and A. Guenther (2003), Seasonal and interannual variability of North American isoprene emissions as determined by formaldehyde column measurements from space, Geophys. Res. Lett., 30(17), 1886, doi:10.1029/2003GL017336.

Atkinson, R. (2000), Atmospheric chemistry of VOCs and $\mathrm{NO}_{\mathrm{x}}$, Atmos. Environ., 34(12-14), 2063-2101.

Atkinson, R., D. L. Baulch, R. A. Cox, J. N. Crowley, J. R. F. Hampson, R. G. Hynes, M. E. Jenkin, J. A. Kerr, M. J. Rossi, and J. Troe (2004), Summary of evaluated kinetic and photochemical data for atmospheric chemistry, IUPAC Subcomm. on Gas Kinet. Data Eval. for Atmos. Chem., Cambridge, U. K.

Beirle, S., U. Platt, M. Wenig, and T. Wagner (2003), Weekly cycle of $\mathrm{NO}_{2}$ by GOME measurements: A signature of anthropogenic sources, Atmos. Chem. Phys., 3, 2225-2232.

Beirle, S., U. Platt, R. von Glasow, M. Wenig, and T. Wagner (2004), Estimate of nitrogen oxide emissions from shipping by satellite remote sensing, Geophys. Res. Lett., 31, L18102, doi:10.1029/2004GL020312.

Bey, I., D. J. Jacob, R. M. Yantosca, J. A. Logan, B. D. Field, A. M. Fiore, Q. B. Li, H. G. Y. Liu, L. J. Mickley, and M. G. Schultz (2001), Global modeling of tropospheric chemistry with assimilated meteorology: Model description and evaluation, J. Geophys. Res., 106(D19), $23,073-23,095$.

Blake, N. J., et al. (2003), NMHCs and halocarbons in Asian continental outflow during the Transport and Chemical Evolution over the Pacific (TRACE-P) Field Campaign: Comparison with PEM-West B, J. Geophys. Res., 108(D20), 8806, doi:10.1029/2002JD003367.

Bloss, C., et al. (2005), Development of a detailed chemical mechanism (MCMv3.1) for the atmospheric oxidation of aromatic hydrocarbons, Atmos. Chem. Phys., 5, 641-664.

Boersma, K. F., H. J. Eskes, and E. J. Brinksma (2004), Error analysis for tropospheric $\mathrm{NO}_{2}$ retrieval from space, J. Geophys. Res., 109, D04311, doi:10.1029/2003JD003962.

Bond, T. C., T. L. Anderson, and D. Campbell (1999), Calibration and intercomparison of filter-based measurements of visible light absorption by aerosols, Aerosol Sci. Technol., 30(6), 582-600.

Burrows, J. P., et al. (1999), The global ozone monitoring experiment (GOME): Mission concept and first scientific results, J. Atmos. Sci., $56(2), 151-175$.

Chance, K., P. I. Palmer, R. J. D. Spurr, R. V. Martin, T. P. Kurosu, and D. J. Jacob (2000), Satellite observations of formaldehyde over North America from GOME, Geophys. Res. Lett., 27(21), 3461-3464.

Claeys, M., et al. (2004a), Formation of secondary organic aerosols through photooxidation of isoprene, Science, 303(5661), 1173-1176.

Claeys, M., W. Wang, A. C. Ion, I. Kourtchev, A. Gelencser, and W. Maenhaut (2004b), Formation of secondary organic aerosols from isoprene and its gas-phase oxidation products through reaction with hydrogen peroxide, Atmos. Environ., 38(25), 4093-4098.

Colman, J. J., A. L. Swanson, S. Meinardi, B. C. Sive, D. R. Blake, and F. S. Rowland (2001), Description of the analysis of a wide range of volatile organic compounds in whole air samples collected during PEM-Tropics $\mathrm{A}$ and B, Anal. Chem., 73(15), 3723-3731.
Czoschke, N. M., M. Jang, and R. M. Kamens (2003), Effect of acidic seed on biogenic secondary organic aerosol growth, Atmos. Environ., 37(30), 4287-4299.

Di Carlo, P., et al. (2004), Missing OH reactivity in a forest: Evidence for unknown reactive biogenic VOCs, Science, 304(5671), 722-725.

Evans, M. J., and D. J. Jacob (2005), Impact of new laboratory studies of $\mathrm{N}_{2} \mathrm{O}_{5}$ hydrolysis on global model budgets of tropospheric nitrogen oxides, ozone, and OH, Geophys. Res. Lett., 32, L09813, doi:10.1029/ 2005GL022469.

Fehsenfeld, F., et al. (1992), Emissions of volatile organic compounds from vegetation and the implications for atmospheric chemistry, Global Biogeochem. Cycles, 6(4), 389-430.

Fiore, A. M., D. J. Jacob, I. Bey, R. M. Yantosca, B. D. Field, A. C. Fusco, and J. G. Wilkinson (2002), Background ozone over the United States in summer: Origin, trend, and contribution to pollution episodes, J. Geophys. Res., 107(D15), 4275, doi:10.1029/2001JD000982.

Fiore, A. M., L. W. Horowitz, D. W. Purves, H. Levy, M. J. Evans, Y. X. Wang, Q. B. Li, and R. M. Yantosca (2005), Evaluating the contribution of changes in isoprene emissions to surface ozone trends over the eastern United States, J. Geophys. Res., 110, D12303, doi:10.1029/2004JD005485.

Fried, A., et al. (2003), Airborne tunable diode laser measurements of formaldehyde during TRACE-P: Distributions and box model comparisons, J. Geophys. Res., 108(D20), 8798, doi:10.1029/2003JD003451.

Frost, G. J., et al. (2002), Comparisons of box model calculations and measurements of formaldehyde from the 1997 North Atlantic Regional Experiment, J. Geophys. Res., 107(D8), 4060, doi:10.1029/2001JD000896.

Fuentes, J. D., et al. (2000), Biogenic hydrocarbons in the atmospheric boundary layer: A review, Bull. Am. Meteorol. Soc., 81(7), 1537-1575.

Goldstein, A. H., M. McKay, M. R. Kurpius, G. W. Schade, A. Lee, R. Holzinger, and R. A. Rasmussen (2004), Forest thinning experiment confirms ozone deposition to forest canopy is dominated by reaction with biogenic VOCs, Geophys. Res. Lett., 31, L22106, doi:10.1029/ 2004GL021259.

Guenther, A., et al. (1995), A global model of natural volatile organic compound emissions, J. Geophys. Res., 100(D5), 8873-8892.

Guenther, A., C. Geron, T. Pierce, B. Lamb, P. Harley, and R. Fall (2000), Natural emissions of non-methane volatile organic compounds, carbon monoxide, and oxides of nitrogen from North America, Atmos. Environ., 34(12-14), 2205-2230.

Guenther, A., T. Karl, P. Harley, C. Wiedinmyer, P. I. Palmer, and C. Geron (2006), Estimates of global terrestrial isoprene emissions using MEGAN (Model of Emissions of Gases and Aerosols from Nature), Atmos. Chem. Phys., 6, 3181-3210.

Hanst, P. L., J. W. Spence, and E. O. Edney (1980), Carbon monoxide production in photooxidation of organic molecules in the air, Atmos. Environ., 14(9), 1077-1088.

Heikes, B., J. Snow, P. Egli, D. O'Sullivan, J. Crawford, J. Olson, G. Chen, D. Davis, N. Blake, and D. Blake (2001), Formaldehyde over the central Pacific during PEM-Tropics B, J. Geophys. Res., 106(D23), 32,717-32,731.

Hild, L., A. Richter, V. Rozanov, and J. P. Burrows (2002), Air mass factor calculations for GOME measurements of lightning-produced $\mathrm{NO}_{2}, A d v$. Space Res., 29(11), 1685-1690.

Holzinger, R., A. Lee, K. T. Paw, and A. H. Goldstein (2005), Observations of oxidation products above a forest imply biogenic emissions of very reactive compounds, Atmos. Chem. Phys., 5, 67-75.

Horowitz, L. W., J. Y. Liang, G. M. Gardner, and D. J. Jacob (1998), Export of reactive nitrogen from North America during summertime: Sensitivity to hydrocarbon chemistry, J. Geophys. Res., 103(D11), $13,451-13,476$.

Irie, H., et al. (2005), Evaluation of long-term tropospheric $\mathrm{NO}_{2}$ data obtained by GOME over East Asia in 1996-2002, Geophys. Res. Lett., 32, L11810, doi:10.1029/2005GL022770.

Jacob, D. J., et al. (1993), Simulation of summertime ozone over North America, J. Geophys. Res., 98(D8), 14,797-14,816.

Jaeglé, L., R. V. Martin, K. Chance, L. Steinberger, T. P. Kurosu, D. J. Jacob, A. I. Modi, V. Yoboue, L. Sigha-Nkamdjou, and C. Galy-Lacaux (2004), Satellite mapping of rain-induced nitric oxide emissions from soils, J. Geophys. Res., 109, D21310, doi:10.1029/2004JD004787.

Jang, M. S., N. M. Czoschke, S. Lee, and R. M. Kamens (2002), Heterogeneous atmospheric aerosol production by acid-catalyzed particle-phase reactions, Science, 298(5594), 814-817.

Koelemeijer, R. B. A., and P. Stammes (1999), Effects of clouds on ozone column retrieval from GOME UV measurements, J. Geophys. Res., 104(D7), 8281-8294

Koelemeijer, R. B. A., P. Stammes, J. W. Hovenier, and J. F. de Haan (2001), A fast method for retrieval of cloud parameters using oxygen A band measurements from the Global Ozone Monitoring Experiment, J. Geophys. Res., 106(D4), 3475-3490.

Koelemeijer, R. B. A., J. F. de Haan, and P. Stammes (2003), A database of spectral surface reflectivity in the range $335-772 \mathrm{~nm}$ derived from 
5.5 years of GOME observations, J. Geophys. Res., 108(D2), 4070, doi:10.1029/2002JD002429.

Konovalov, I. B., M. Beekmann, R. Vautard, J. P. Burrows, A. Richter H. Nuss, and N. Elansky (2005), Comparison and evaluation of modelled and GOME measurement derived tropospheric $\mathrm{NO}_{2}$ columns over western and eastern Europe, Atmos. Chem. Phys., 5, 169-190.

Kurosu, T. P., K. Chance, and R. J. D. Spurr (1999), CRAG: Cloud Retrieval Algorithm for the European Space Agency's Global Ozone Monitoring Experiment, in Proceedings of the European Symposium of Atmospheric Measurements From Space, pp. 513-521, Eur. Space Agency, Paris.

Kurpius, M. R., and A. H. Goldstein (2003), Gas-phase chemistry dominates $\mathrm{O}_{3}$ loss to a forest, implying a source of aerosols and hydroxyl radicals to the atmosphere, Geophys. Res. Lett., 30(7), 1371, doi:10.1029/ 2002GL016785.

Ladstatter-Weissenmayer, A., J. Heland, R. Kormann, R. von Kuhlmann, M. G. Lawrence, J. Meyer-Arnek, A. Richter, F. Wittrock, H. Ziereis, and J. P. Burrows (2003), Transport and build-up of tropospheric trace gases during the MINOS campaign: Comparison of GOME, in situ aircraft measurements and MATCH-MPIC-data, Atmos. Chem. Phys., 3, 1887-1902.

Lauer, A., M. Dameris, A. Richter, and J. P. Burrows (2002), Tropospheric $\mathrm{NO}_{2}$ columns: A comparison between model and retrieved data from GOME measurements, Atmos. Chem. Phys., 2, 67-78.

Lee, Y. N., et al. (1998), Atmospheric chemistry and distribution of formaldehyde and several multioxygenated carbonyl compounds during the 1995 Nashville Middle Tennessee Ozone Study, J. Geophys. Res., 103(D17), 22,449-22,462.

Leue, C., M. Wenig, T. Wagner, O. Klimm, U. Platt, and B. Jahne (2001), Quantitative analysis of $\mathrm{NO}_{\mathrm{x}}$ emissions from Global Ozone Monitoring Experiment satellite image sequences, J. Geophys. Res., 106(D6), 54935505.

Levis, S., C. Wiedinmyer, G. B. Bonan, and A. Guenther (2003), Simulating biogenic volatile organic compound emissions in the Community Climate System Mode1, J. Geophys. Res., 108(D21), 4659, doi:10.1029/2002JD003203.

Levy, H. (1972), Photochemistry of the lower troposphere, Planet. Space Sci., 20(6), 919-935.

Lim, H. J., A. G. Carlton, and B. J. Turpin (2005), Isoprene forms secondary organic aerosol through cloud processing: Model simulations, Environ. Sci. Technol., 39(12), 4441-4446.

Limbeck, A., M. Kulmala, and H. Puxbaum (2003), Secondary organic aerosol formation in the atmosphere via heterogeneous reaction of gaseous isoprene on acidic particles, Geophys. Res. Lett., 30(19), 1996, doi:10.1029/2003GL017738.

Lowe, D. C., and U. Schmidt (1983), Formaldehyde (HCHO) measurements in the nonurban atmosphere, J. Geophys. Res., 88(15), 844-858

Marquard, L. C., T. Wagner, and U. Platt (2000), Improved air mass factor concepts for scattered radiation differential optical absorption spectroscopy of atmospheric species, J. Geophys. Res., 105(D1), 1315-1327.

Martin, R. V., et al. (2002a), An improved retrieval of tropospheric nitrogen dioxide from GOME, J. Geophys. Res., 107(D20), 4437, doi:10.1029/ 2001JD001027.

Martin, R. V., et al. (2002b), Interpretation of TOMS observations of tropical tropospheric ozone with a global model and in situ observations, J. Geophys. Res., 107(D18), 4351, doi:10.1029/2001JD001480.

Martin, R. V., D. J. Jacob, K. Chance, T. P. Kurosu, P. I. Palmer, and M. J. Evans (2003a), Global inventory of nitrogen oxide emissions constrained by space-based observations of $\mathrm{NO}_{2}$ columns, J. Geophys. Res., 108(D17), 4537, doi:10.1029/2003JD003453.

Martin, R. V., D. J. Jacob, R. M. Yantosca, M. Chin, and P. Ginoux (2003b), Global and regional decreases in tropospheric oxidants from photochemical effects of aerosols, J. Geophys. Res., 108(D3), 4097, doi:10.1029/ 2002JD002622.

Martin, R. V., D. D. Parrish, T. B. Ryerson, D. K. Nicks, K. Chance, T. P. Kurosu, D. J. Jacob, E. D. Sturges, A. Fried, and B. P. Wert (2004), Evaluation of GOME satellite measurements of tropospheric $\mathrm{NO}_{2}$ and $\mathrm{HCHO}$ using regional data from aircraft campaigns in the southeastern United States, J. Geophys. Res., 109, D24307, doi:10.1029/2004JD004869.

Meyer-Arnek, J., A. Ladstatter-Weissenmayer, A. Richter, F. Wittrock, and J. P. Burrows (2005), A study of the trace gas columns $\mathrm{O}_{3}, \mathrm{NO}_{2}$ and HCHO over Africa in September 1997, Faraday Disc., 130, $387-$ 405.

Naik, V., C. Delire, and D. J. Wuebbles (2004), Sensitivity of global biogenic isoprenoid emissions to climate variability and atmospheric $\mathrm{CO}_{2}$, J. Geophys. Res., 109, D06301, doi:10.1029/2003JD004236.

Noxon, J. F., E. C. Whipple, and R. S. Hyde (1979), Stratospheric $\mathrm{NO}_{2}$ : 1. Observational method and behavior at mid-latitude, J. Geophys. Res. 84(8), 5047-5065.

Palmer, P. I., D. J. Jacob, K. Chance, R. V. Martin, R. J. D. Spurr, T. P Kurosu, I. Bey, R. Yantosca, A. Fiore, and Q. B. Li (2001), Air mass factor formulation for spectroscopic measurements from satellites: Application to formaldehyde retrievals from the Global Ozone Monitoring Experiment, J. Geophys. Res., 106(D13), 14,539-14,550.

Palmer, P. I., D. J. Jacob, A. M. Fiore, R. V. Martin, K. Chance, and T. P. Kurosu (2003), Mapping isoprene emissions over North America using formaldehyde column observations from space, J. Geophys. Res. 108(D6), 4180, doi:10.1029/2002JD002153.

Palmer, P. I., et al. (2006), Quantifying the seasonal and interannual variability of North American isoprene emissions using satellite observations of formaldehyde column, J. Geophys. Res., 111, D12315, doi:10.1029/ 2005JD006689.

Park, R. J., D. J. Jacob, M. Chin, and R. V. Martin (2003), Sources of carbonaceous aerosols over the United States and implications for natural visibility, J. Geophys. Res., 108(D12), 4355, doi:10.1029/2002JD003190. Park, R. J., D. J. Jacob, B. D. Field, R. M. Yantosca, and M. Chin (2004), Natural and transboundary pollution influences on sulfate-nitrateammonium aerosols in the United States: Implications for policy, J. Geophys. Res., 109, D15204, doi:10.1029/2003JD004473.

Perliski, L. M., and S. Solomon (1993), On the evaluation of air mass factors for atmospheric near-ultraviolet and visible absorption spectroscopy, J. Geophys. Res., 98(D6), 10,363-10,374.

Pfister, G., P. G. Hess, L. K. Emmons, J. F. Lamarque, C. Wiedinmyer, D. P. Edwards, G. Petron, J. C. Gille, and G. W. Sachse (2005), Quantifying $\mathrm{CO}$ emissions from the 2004 Alaskan wildfires using MOPITT CO data, Geophys. Res. Lett., 32, L11809, doi:10.1029/2005GL022995.

Potter, C. S., S. E. Alexander, J. C. Coughlan, and S. A. Klooster (2001), Modeling biogenic emissions of isoprene: Exploration of model drivers, climate control algorithms, and use of global satellite observations, Atmos. Environ., 35(35), 6151-6165.

Richter, A., and J. P. Burrows (2002), Tropospheric $\mathrm{NO}_{2}$ from GOME measurements, Adv. Space Res., 29(11), 1673-1683.

Richter, A., V. Eyring, J. P. Burrows, H. Bovensmann, A. Lauer, B. Sierk, and P. J. Crutzen (2004), Satellite measurements of $\mathrm{NO}_{2}$ from international shipping emissions, Geophys. Res. Lett., 31, L23110, doi:10.1029/ 2004GL020822.

Roller, C., A. Fried, J. Walega, P. Weibring, and F. Tittel (2006), Advances in hardware, system diagnostics software, and acquisition procedures for high performance airborne tunable laser measurements of formaldehyde, Appl. Phys. B, 82, 247-264

Sander, S. P., et al. (2002), Chemical kinetics and photochemical data for use in atmospheric studies: Evaluation number 14, JPL Publ. 02-25, Jet Propul. Lab., Pasadena, Calif.

Sanderson, M. G., C. D. Jones, W. J. Collins, C. E. Johnson, and R. G. Derwent (2003), Effect of climate change on isoprene emissions and surface ozone levels, Geophys. Res. Lett., 30(18), 1936, doi:10.1029/ 2003GL017642.

Savage, N. H., K. S. Law, J. A. Pyle, A. Richter, H. Nuss, and J. P. Burrows (2004), Using GOME $\mathrm{NO}_{2}$ satellite data to examine regional differences in TOMCAT model performance, Atmos. Chem. Phys. 4, 1895-1912.

Shepson, P. B., D. R. Hastie, H. I. Schiff, M. Polizzi, J. W. Bottenheim, K. Anlauf, G. I. Mackay, and D. R. Karecki (1991), Atmospheric concentrations and temporal variations of $\mathrm{C}_{1}-\mathrm{C}_{3}$ carbonyl compounds at 2 rural sites in central Ontario, Atmos. Environ., Part A, 25(9), 2001-2015.

Shim, C., Y. Wang, Y. Choi, P. I. Palmer, D. S. Abbot, and K. Chance (2005), Constraining global isoprene emissions with Global Ozone Monitoring Experiment (GOME) formaldehyde column measurements, J. Geophys. Res., 110, D24301, doi:10.1029/2004JD005629.

Singh, H. B., and P. B. Zimmerman (1992), Atmospheric distribution and sources of nonmethane hydrocarbons, in Gaseous Pollutants: Characterization and Cycling, edited by J. O. Nriagu, pp. 177-235, John Wiley, Hoboken. N. J.

Singh, H., et al. (2000), Distribution and fate of selected oxygenated organic species in the troposphere and lower stratosphere over the Atlantic, J. Geophys. Res., 105(D3), 3795-3805.

Singh, H. B., et al. (2004), Analysis of the atmospheric distribution, sources, and sinks of oxygenated volatile organic chemicals based on measurements over the Pacific during TRACE-P, J. Geophys. Res., 109, D15S07, doi:10.1029/2003JD003883.

Spichtinger, N., R. Damoah, S. Eckhardt, C. Forster, P. James, S. Beirle, T. Marbach, T. Wagner, P. C. Novelli, and A. Stohl (2004), Boreal forest fires in 1997 and 1998: A seasonal comparison using transport model simulations and measurement data, Atmos. Chem. Phys., 4, 1857-1868.

Spurr, R. J. D., T. P. Kurosu, and K. V. Chance (2001), A linearized discrete ordinate radiative transfer model for atmospheric remote-sensing retrieval, J. Quant. Spectrosc. Radiat. Transfer, 68(6), 689-735.

Stohl, A., et al. (2003), Rapid intercontinental air pollution transport associated with a meteorological bomb, Atmos. Chem. Phys., 3, 969985.

Thomas, W., E. Hegels, S. Slijkhuis, R. Spurr, and K. I. Chance (1998), Detection of biomass burning combustion products in Southeast Asia 
from backscatter data taken by the GOME spectrometer, Geophys. Res. Lett., 25(9), 1317-1320.

Tuinder, O. N. E., R. de Winter-Sorkin, and P. J. H. Builtjes (2004), Retrieval methods of effective cloud cover from the GOME instrument: An intercomparison, Atmos. Chem. Phys., 4, 255-273.

Velders, G. J. M., C. Granier, R. W. Portmann, K. Pfeilsticker, M. Wenig, T. Wagner, U. Platt, A. Richter, and J. P. Burrows (2001), Global tropospheric $\mathrm{NO}_{2}$ column distributions: Comparing three-dimensional model calculations with GOME measurements, J. Geophys. Res., 106(D12), $12,643-12,660$.

Virkkula, A., N. C. Ahlquist, D. S. Covert, W. P. Arnott, P. J. Sheridan, P. K. Quinn, and D. J. Coffman (2005), Modification, calibration and a field test of an instrument for measuring light absorption by particles, Aerosol Sci. Technol., 39(1), 68-83.

Wagner, V., R. von Glasow, H. Fischer, and P. J. Crutzen (2002), Are $\mathrm{CH}_{2} \mathrm{O}$ measurements in the marine boundary layer suitable for testing the current understanding of $\mathrm{CH}_{4}$ photooxidation?: A model study, J. Geophys. Res., 107(D3), 4029, doi:10.1029/2001JD000722.

Wang, K. Y., and D. E. Shallcross (2000), Modelling terrestrial biogenic isoprene fluxes and their potential impact on global chemical species using a coupled LSM-CTM model, Atmos. Environ., 34(18), 2909-2925.

Wert, B. P., A. Fried, S. Rauenbuehler, J. Walega, and B. Henry (2003), Design and performance of a tunable diode laser absorption spectrometer for airborne formaldehyde measurements, J. Geophys. Res., 108(D12), 4350, doi:10.1029/2002JD002872.

Xiao, Y. P., D. J. Jacob, J. S. Wang, J. A. Logan, P. I. Palmer, P. Suntharalingam, R. M. Yantosca, G. W. Sachse, D. R. Blake, and D. G. Streets (2004), Constraints on Asian and European sources of methane from $\mathrm{CH}_{4}-\mathrm{C}_{2} \mathrm{H}_{6}$ - $\mathrm{CO}$ correlations in Asian outflow, J. Geophys. Res., 109, D15S16, doi:10.1029/2003JD004475.

Zhang, R. Y., I. Suh, J. Zhao, D. Zhang, E. C. Fortner, X. X. Tie, L. T. Molina, and M. J. Molina (2004), Atmospheric new particle formation enhanced by organic acids, Science, 304(5676), 1487-1490.

Zimmerman, P. R., R. B. Chatfield, J. Fishman, P. J. Crutzen, and P. L. Hanst (1978), Estimates on production of $\mathrm{CO}$ and $\mathrm{H}_{2}$ from oxidation of hydrocarbon emissions from vegetation, Geophys. Res. Lett., 5(8), 679-682.

B. E. Anderson, Atmospheric Sciences Division, NASA Langley Research Center, Hampton, VA 23681, USA

D. R. Blake, Department of Chemistry, University of California, Irvine, CA 92697, USA.

A. D. Clarke, School of Ocean and Earth Science and Technology, University of Hawaii at Manoa, Honolulu, HI 96822, USA.

A. Fried and J. Walega, Earth Observing Laboratory, National Center for Atmospheric Research, Boulder, CO 80307, USA.

B. G. Heikes, Graduate School of Oceanography, University of Rhode Island, Narragansett, RI 02882, USA.

R. C. Hudman, D. J. Jacob, D. B. Millet, and S. Wu, Department of Earth and Planetary Sciences and Division of Engineering and Applied Sciences, Harvard University, Cambridge, MA 02138, USA. (dbm@io.harvard.edu)

H. B. Singh, NASA Ames Research Center, Moffett Field, CA 94035, USA.

S. Turquety, Service d'Aéronomie, Institut Pierre-Simon Laplace, Universite Pierre et Marie Curie, Boite 102, 4, place Jussieu, F-75252 Paris Cedex 05, France. 